\title{
Situación política en vísperas de mayo de 1968
}

\begin{abstract}
ENRIQUE BERNSTEIN es antiguo funcionario del Servicio Exterior de Chile. Ingres $\delta$ al Ministerio de Relaciones Exteriores, por concurso, en el último grado del escalafón y ahora ocupa el más alto grado del mismo. Todos sus ascensos fueron "por mé" rito". Fue, sucesivamente, Director del Departamento Diplomá. tico, Jefe del Protocolo, Asesor Político, Director General del Ministerio y Subsecretario de Relaciones Exteriores. Ha sido, asimismo, Embajador en Austria y Yugoslavia $y$, durante seis años, Embajador en Paris. Delegado a numerosas conferencias internacionales, presidió la Delegación chílena a la Asamblea General de las Naciones Unidas, en 1964.

Durante su estada en Paris, fue testigo presencial de la llamada "Revolución de Mayo".

Publicamos, a continuación, como una primicia, el capítulo de sus Memorias referente a este acontecimiento, y que forma parte de un libro, Misión en Francia, que está en preparación y será editado en breve.
\end{abstract}

18 de marzo

La sesión parlamentaria ordinaria que se inaugura el mes próximo se anuncia cargada de electricidad. La Oposición y el Gobierno se van a enfrentar con una fogosidad no acostumbrada en los últimos años. Ello se debe al ambiente político cada vez más tenso y a varios factores que se han venido desenvolviendo durante las vacaciones de invierno. Desde luego, debido al abandono de un diputado autonomista de Polinesia, el Gobierno ha quedado en minoría en la Asamblea Nacional y, en todas las votaciones importantes, deberá contar ahora con algunos votos del Centro. En seguida, la Oposición ha solidificado sus estructuras en estas últimas semanas con la decisión de radicales, socialistas y representantes de lo llamados "clubes" republicanos, de crear un nuevo partido político, la Federación de Izquierda; y con la firma de un pacto de acción electoral y gubernativa entre la Federación y el Partido Comunista.

Dentro de la Federación, y mientras se logra la unificación, se ha creado un Comité Directivo con franca predominancia de los 
socialistas. Los radicales han aceptado quedar en la proporción de uno a cuatro con respecto a los demás integrantes del Comité. Aun cuando esta situación minoritaria no sea del agrado de los jefes del otrora partido radical, es un hecho que ella ha sido aceptada por las bases y ya es difícil establecer diferencias ideológicas entre un militante socialista y un radical.

El problema de las relaciones entre la Federación ý el Partido Comunista es más difícil de resolver, aunque existe un interés recíproco por llegar a un acuerdo. Debido al sistema electoral francés de doble rueda electoral en caso de no existir mayoría absoluta, el apoyo comunista en la segunda rueda le es indispensable a la Izquierda si desea ser mayoría en las elecciones presidenciales o parlamentarias. En cuanto al Partido Comunista, que progresivamente ha logrado salir del "ghetto" en que se encontraba desde hace veinte años, desea ahora legalizar su situación de partido "nacional" mediante un entendimiento, no sólo electoral, sino que también sobre un programa de gobierno. Sus vivos deseos de ingresar a un Frente Popular con eventual participación gubernativa, lo ha hecho ser más ductil y menos dogmático, lo que facilitó un acuerdo que ambas partes anhelan.

El pacto firmado ha tenido dos efectos contradictorios inmediatos. El gaullismo puro y sus aliados "giscardianos" 1 han iniciaclo una violenta ofensiva contra ese "matrimonio contra-natura", señalando los peligros que, para Francia, entrañaria un triunfo de la Izquierda unida al Partido Comunista. El aniversario del golpe de 1947 en Praga, el defenestramiento de Tomas Mazaryk, la liquidación del centro y del socialismo checoslovacos, el establecimiento del estalinismo en un país que fuera modelo de democracia, han dado origen a una campaña destinada a asustar a la masa independiente. Una frase un tanto desgraciada, del pacto firmado, ha sido insistentemente esgrimida por los partidos de gobierno. Se hace mención, en dicho pacto, a las medidas que tomaría la alianza Federación-Comunista en caso de triunfar y para evitar que el pueblo sea defraudado. EI primer Ministro Georges Pompidou y los líderes gaullistas han denunciado en ellas una amenaza para las libertades públicas y el anuncio de medidas dictatoriales. En vano, François Mitterand ha explicado que dichas medidas se refieren a evitar una eventual fuga de capitales: el temor ha cundido y ha perjudicado a la Izquierda.

Por otra parte, los recientes acontecimientos en Polonia y Checoslovaquia ${ }^{2}$ que no han prestigiado al sistema comunista tradicional,

${ }^{1}$ Del nombre de su líder Valéry Giscard d'Estaing.

"Movimientos estudiantiles y de tipo "libertario"; surgidos en 1968. 
han creado suspicacias y temores no sólo en el sector más moderado de la Federación, sino que también en el propio partido socialista. El periódico Le Figaro ha publicado una caricatura que representa a los tres líderes de la Oposición, Waldeck Rochet, Guy Mollet y François Mitterand en la actitud de los "tres monos asiáticos" (no hablo, no veo, no escucho) que son observados, con expresión meditabunda por el Presidente del partido radical a medida que lee noticias de Bucarest, de Varsovia y de Praga.

Pero el acuerdo de eventual gobierno entre la Federación y el Partido Comunista ha provocado también una visible decepción en algunos círculos de Izquierda. Unos se quejan de que el "conservantismo" y la "inamovilidad" comunista podría impedir un programa destinado a lograr la unidad europea. Se sabe, en efecto, que no existió acuerdo entre los recientes aliados sobre la política externa cle Francia: mientras los comunistas se oponen a la integración. política de Europa, los "federados" la consideran esencial. El Partido Comunista califica de "renuncio a la soberanía" la integración política y coincide con el pensamiento del General Charles de Gaulle.

Pero, además, el programa del contra-gobierno ha defraudado a los elementos tecnócratas de la Izquierda por su demagogia. En efecto, dicho programa enumera, por una parte, las medidas para incrementar los gastos públicos (aumento de salarios y de cargas sociales, duplicación de habitaciones obreras, nacionalización de los bancos, etc.); pero, al propio tiempo, propicia la disminución de ciertos impuestos y el incremento de otros, el establecimiento de un impuesto especial sobre la plusvalía del capital y sobre las grandes fortunas. Un análisis de ambas medidas, hecho por un periodista de izquierda, Roger Priouret, demuestra que las mayores entradas no llegarían a cubrir ni la décima parte de los gastos previstos. El caso de la cesantía es típico. El programa de la Oposición prevé la reducción de la jornada de trabajo de 45 a 40 horas y la disminución de la edad de jubilación. Con la aplicación del programa se daría trabajo a 400.000 actuales cesantes; pero significaría el retiro de la actividad de un millón de personas. Además, la semana de 40 horas equivale a la disminución de dos millones de trabajadores en pleno. empleo actualmente. Se calcula en un diez por ciento la disminución de la producción, junto a un aumento de los salarios. Resultado: la inflación "ad portas". Con no poca razón, Waldeck Rochet ha sostenido que el programa de un gobierno de Izquierda es sólo una plataforma política.

De allí la decepción y el temor de que si François Mitterand, la Federación y el Partido Comunista llegasen al gobierno, repetirían 
los mismos errores que cometió la Izquierda en el pasado, en 1924, en 1932, en 1936 y en 1956 con sus consecuencias bien conocidas, a saber que al cabo de dos años, como máximo, perdió el poder por carecer de una política financiera realista.

A medida que la oposición se aglutina, se fortalece la personaliclad de François Mitterand como su Jefe máximo. Personaje muy cliscutido hasta la elección presidencial de 1965, que inspiró desconfianza clespués, ha conseguido ahora una posición descollante $y$ ha demostrado suma habilidad para suavizar asperezas. Ha sido -el verdadero autor del pacto aglutinador de la Izquierda, en desmedro de la posición de Pierre Mendes-France, quien se ha mantenido, como siempre, aislado, al margen de estas actividades. Con su micro partido, el PSU (Partido Socialista Unido), sigue actuando como francotirador, capaz, inteligente como el que más, pero sin Juestes organizadas que lo sigan.

En la mayoria, está sucediendo un fenómeno parecido. Georges Pompidou ha conseguido eliminar de entre los "presidenciables", al menos por el momento, a Valéry Giscard d'Estaing, quien se clesprestigia un tanto con su política del "oui... mais" (sí.... pero), con sus eternas reticencias para ingresar a la mayoría. El Primer Ministro está demostrando condiciones cle oraclor político y de verdaclero líder en sus ataques a la Oposición. Frente a la izquierda más o menos unificada, se perfila como el único "Delfín".

Entre ambas formaciones, el Centro aparece como un conglomerado que no atrae, sino que puede ser atraído. Por el momento, parece demostrar mayor interés por oír las voces de sirena del gauilismo. Su sector más avanzado se siente defraudado por la exclusión que el Partido Comunista ha lanzado en su contra. Quienes propiciaban una apertura a la sinistra no han encontrado eco. Entre un pacto con el centro o con los comunistas, la Federación: ha elegiclo la segunda solución, electoralmente más rentable. El espectro -del Frente Popular pena todavía a muchos centristas y a la burguesía, que constituye su fuerza más numerosa. Los más reacios a un acercamiento con el gobierno son los antiguos MRP, especialmente Lecanuet y Abelin.

Todo esto hace prever una vida parlamentaria agitada en los próximos meses. Pero esta agitación no alcanza a otros sectores del país. Francia está rica; se come bien y hay orden. Viansson Pontet acaba de escribir en Le Monde un artículo según el cual "Francia se aburre". Algo recuerda, en efecto, los tiempos de Luis Felipe, hace más cle un siglo. Es evidente que la guerra del Vietnam; conmueve a la opinión pública, pero nadie está dispuesto a. sacrificarse por la causa cle la independencia de las ex colonias. Es cierto que 
la crisis de Medio Oriente provocó el entusiasmo del país en favor de Israel; pero ese entusiasmo duró poco y ahora la opinión pública está encontrando razonable la posición de Charles De Gaulles. Las guerrillas en América Latina están de moda aún, pero no traspasan el marco de los sociólogos de izquierda o de reuniones de intelectuales, incapaces de sacrificarse personalmente, como Regis Debray. El pueblo francés, que se agitó el siglo pasado en favor de los patriotas griegos $y$ de las luchas libertarias en el mundo, no se conmueve mayormente ante la dictadura militar de Atenas, ni ante el medio millón de asesinados en Indonesia o ante los horrores del genocidio de Biafra. La juventud francesa parece estar paralizada por la paz interna, la falta de amenaza exterior o la carencia de grandes ideales.

Sin embargo, hay algo de efectivo en esto de que "Francia se aburre". Se aburre la burguesía dentro de su riqueza, se aburre el obrero de sus reclamos periódicos y nunca oíclos, se aburren los estadistas, a pesar de sus querellas parlamentarias, se aburre el General Charles de Gaulle de inaugurar exposiciones de flores, de agricultura o de estadios deportivos. Sobre todo, se aburre la juventud: y sus preocupaciones mayores consisten en saber si las autoridades permitirán, en los internados universitarios, las visitas recíprocas en los dormitorios de ambos sexos.

Lo único inquietante es que un artículo, con el mismo título deI de Viansson-Pontet, fue publicado, según me ha contado Louis Joxe 4 , en enero de 1848 por Lamartine, poco antes de la gran revolución de 1848, que tantos muertos dejó en Francia y que trajo consigo la proclamación de la Segunda República. Parece que èl aburrimiento es mal consejero en este pais.

Para mirar las cosas con imparcialidad, bastaría seguir la encuesta que, a petición de Le Figaro ha realizado Sofres, la empresa encargada de sondear a la opinión pública. El $61 \%$ de los franceses apoyan la política exterior de Charles de Gaulle; sólo un $9 \%$ consideran muy buena la política económica y $44 \%$ "bastante buena". Sólo un $37 \%$ aprueban, en cambio, la política social, encontrándola "bastante buena" (apenas un $5 \%$ la hallan "múy buena"). Un $42 \%$ la desaprueban.

Respecto a la personalidad del General, un $50 \%$ lo encuentran preferible entre los demás políticos franceses y hubo $24 \%$ sin opinión.

${ }^{3}$ En favor de los árabes.

LLouis Joxe, Vice-Primer Ministro. 
La Asamblea Nacional ha reanudado sus sesiones ordinarias. Desdeel primer dia, el lenguaje ha sido duro y agresivo y el Presidente, Jacques Chaban-Delmas, tuvo dificultades en mantener el orden. La Oposición ha presentado un voto de censura contra el Ministerio por su política general. Según la Constitución, para que ella sea aprobada, necesita la mayoría absoluta de los diputados en ejercicio. Dudo que sea aprobada. En efecto, el Centro Demócrata y los. independientes, que inclinan la balanza en los escrutinios, saben que si la moción de censura es aprobada, el General Charles de Gaulle no vacilaría en disolver al Parlamento y buen número de sus diputados no tienen el menor deseo de volver ante sus electores. un año apenas después de haber sido elegidos. Por las conversaciones que he sostenido con varios Ministros, he notado mucha confianza no sólo en el rechazo de la moción de censura, sino que también un gran optimismo en ganar las elecciones en el evento. de que aquella fuese aprobada y el Parlamento disuelto. Pero: pasada esta primera batalla, vendrán otras. Se habla ya de una nueva moción de censura, mucho más peligrosa para el Gobierno, sobre su política social y económica.

Lo curioso es que el problema estudiantil no parece preocupar a los parlamentarios. Hace tres semanas, el 22 de marzo, en la Universidad de Nanterre, a escasos kilómetros de París, la Facultad de Letras se animó súbitamente por un problema derivado de las. visitas recíprocas que en el internado se hacían los estudiantes de ambos sexos. El problema, considerado con simpatía por la opinión pública, siempre sensible a lo que diga relación con lo sexual, se complicó por la violencia de un grupo de alumnos que demostraron el más absoluto desprecio por la autoridad. Tomando pretexto de un problema menor, pero que, a su juicio, demostraba el anacronismo de la Universidad, dicho grupo se apoderó de las salas. de clases y exigió reformas de fondo en los métodos de enseñanza. Este descontento fue explotado de inmediato por el Partido Comunista que pretendió desviarlo a la lucha contra la guerra del Vietnam. A su vez, la formación de extrema-derecha "Occidente", se lanzó a. la lucha violenta y la Facultad ha sido cerrada por algunos días. Pero, los estudiantes que habían iniciado la agitación, desagradados por la explotación política que había querido dársele, formaron eI llamado "Movimiento del 22 de Marzo", que reúne las más variadas tendencias: trotskistas, pekinistas, anarquistas, pacifistas, cristianos extremistas, etc., todos unidos no en favor de algo, sino que en 
-contra de todo, de la indiferencia general, del egoísmo, de la "esclerosis" de un sistema, de los métodos anacrónicos de la enseñanza, de la falta de perspectivas para el futuro, en una palabra de lo que llaman la burguesía. Forman todos ellos un grupo heterogéneo, que no obedece a directivas determinadas y no las desea. La única influencia que reconocen es la del profesor judío alemán que enseña en la Uiniversidad de California, en los Estados Unidos, Herbert Marcuse. Este, aunque con setenta años de edad, parece ser el teórico de la juventud descontenta en la actualidad.

\section{9 de abril}

El Comité Central del Partido Comunista se acaba de reunir. El informe del Secretario General, Waldeck Rochet, no escondió las divergencias que separan a su partido de las otras organizaciones de izquierda e hizo algunos comentarios sobre los últimos acontecimientos de Ghecoslovaquia y de Polonia. Respecto a la "pequeña frase" del Pacto con la Federación, dio la misma explicación que había dado antes François Mitterand: si se forma un Gobierno de Izquierda, habrá que tomar medidas para impedir que el podẹr financiero -y vaya que es importante en Francia- haga fracasar la experiencia como sucedió en el pasado, sobre todo mediante la fuga de capitales. En cuanto a la política social y económica señạlada en el Pacto, Waldeck Rochet reconoció discrepancias entre la Federación y su propio partido: mientras la primera desea sólo la nacionalización de los bancos y de las industrias de armamentọ y de investigación espacial, los comunistas quieren extenderla progresivamente a los grandes monopolios industriales que dominan los sectores básicos de la economía, tales como la electrónica, la aeronáutica y el transporte aéreo, los grandes trusts de la química, dẹ la siderurgia y de los automóviles. Respecto al Gobierno del General, reconoció que sería "un grave error pensar que el poder personal va a caer solo o que está tan usado y desacreditado que carezca. de recursos para durar todavía más... aún más allá del propio General de Gaulle".

Respecto al problema base de una colaboración entre las fuerzas democráticas y el Partido Comunista, el Secretario General respondió en los siguientes términos: "Nosotros decimos que en un país comọ Francia, en que la existencia de varios partidos forma parte de la tradición democrática, la cooperación estrecha y durable entre el Partido Comunista y los otros partidos democráticos puede contribuir a acelerar la transformación socialista de Francia dentro de la pluralidad de partidos. Pero ello supone que los partidos democrá- 
ticos que se dicen socialistas, se alejen definitivamente de una colaboración con la burguesía y apliquen, en cambio, una política de lucha efectiva en favor de la democracia y del socialismo". Por ello, Waldeck Rochet insistió en que el Pacto con la Federación era sólo una etapa, que debiera completarse con un programa común de gobierno.

Fácil es prever las repercusiones que estas interpretaciones y estos criterios van a tener dentro de la Federación y, especialmente, dentro de los radicales - burgueses por excelencia- que la integran; y el partido que el Gobierno les va a sacar en los próximos debates parlamentarios para demostrar la falta de cohesión de las fuerzas opositoras. Lo propio va a suceder con las opiniones del Secretario General del Particlo Comunista respecto a los últimos acontecimientos de Checoslovaquia y de Polonia. Acerca de los primeros, señaló que los "comunistas checoslovacos están animados del deseo de impedir que los fundamentos mismos de la sociedad socialista puedan ser amenazados". Refiriéndose al necesario distingo entre las declaraciones de "elementos irresponsables" y las posiciones adoptadas por el Particlo Comunista checo, insistió en las recientes declaraciones de Alexander Dubcek: no alteración cle los principios del socialismo; corrección cle los errores "pero sin arrojar por la ventana al pasado", mantenimiento del papel preponderante del Partido, respecto de las reglas de la "democracia socialista", intangibilidad de la alianza con la URSS y los demás países socialistas. Por todo ello, manifestó su seguridad de que el socialismo perdurará en Checoslovaquia y expresó a Alexander Dubcek sus mejores votos de éxito en su política de desarrollo del socialismo.

En lo que respecta a Polonia, el Secretario General insistió en - la importancia que aún conservan en ese país las fuerzas reaccionarias: A su juicio, los estudiantes han sido soliviantados por un "puñado de elementos antisoviéticos y reaccionarios y por los sionistas, lo cual no significa que el Partido Comunista sea antisemita".

Creo que tampoco estas declaraciones han de producir intima satisfacción en los actuales aliados del comunismo, ya que no han trepidado en manifestar su interés por la liberación en Checoslovaquia y su preocupación por la represión contra los estudiantes en Varsovia. Georges Pompidou, con la habilidad que le caracteriza, va a aprovechar este abundante material para demostrar que la Oposición carece de conceptos claros no sólo en materia de política exterior, sino que también en política interna y económica y que el concepto de Democracia y de Libertad es diferente para los miembros de la Federación y para el Partido Comunista. 
He acompañado a Bernardo Leighton, invitado oficialmente a Francia, a visitar M. Fouchet ${ }^{5}$. Tanto en la visita como en el almuerzo posterior que le fue ofrecido, preguntamos sobre los problemas estudiantiles de Nanterre. M. Fouchet no les dio la menor importancia, estimanclo que la gran mayoría de los jóvenes sólo quieren estudiar y terminar el año universitario con éxito.

En la tarde visitamos al Prefecto de Policía, M. Grimauld, hombre dulce, suave, tranquilo y muy "civil". Nos hizo una demostración de los medios preventivos con que cuenta (televisión, mapa de París en gran escala, con luces para "puntos álgidos"). Se demostró seguro de disolver pacíficamente cualquier demostración de estudiantes.

\section{5 de abril}

Muy interesante visita con Bernardo Leighton a Roger Frey, actual Ministro de Estado para las Relaciones con el Parlamento. Fue, hasta hace poco, Ministro del Interior y debió hacer frente a todas las insurrecciones y desórdenes derivados de la guerra de Argelia. Nos explica cómo, en los momentos más difíciles para el mantenimiento del orden público, jamás quiso echar mano del Ejército, utilizando solamente a la Policía y a las Compañías Republicanas de Seguridad. A su juicio, y le sobra razón, el empleo del Ejército puede ser fatal para mantener el orclen: los jóvenes conscriptos se asustan y disparan cuando no es necesario; la tropa "de métier" (de oficio), en cambio, si hace uso de sus armas, puede causar estragos tremendos, justamente por su preparación y por no estar preparada para los combates callejeros.

En la tarde, visitamos al Rector de la Universidad de París, M. Roche. Bernardo Leighton le pregunta intensamente sobre los problemas estudiantiles. Nos da una versión parecida a la de M. Fouchet y muy tranquilizadora. A su juicio la agitación está circunscrita a Nanterre y no puede cundir un movimiento tan negativo como el que allí predomina.

\section{0 de abril}

Hoy cené con André Bettencourt, Secretario de Estado de Relaciones Exteriores, quien parte a Rumania con el General Charles

Ministro del Interior de Francia.: 
de Gaulle. Tampoco manifiesta preocupación por la agitación estudiantil. Está, en cambio, muy satisfecho por el rechazo del voto de censura presentado por la Oposición contra el Ministro Georges Pompidou. Sin embargo, la victoria de éste fue muy estrecha. Como los cómputos habian sido previa y prolijamente revisados, varios independientes y disputados del Centro Demócrata se dieron el lujo de votar contra el Gobierno.

Georges Pompidou estuvo no sólo violento en sus ataques contra la Oposición, sino que se demostró inflexible y no aceptó ninguna transacción. Aun cuando ninguno de los "giscardianos" dio sus votos a la moción de censura, quedó de manifiesto que discrepaban, en el fondo, de la materia en debate. Más aún, se produjo un cambio de palabras, cortés pero amargo, entre Georges Pompidou y Valéry Giscard d'Estaing quien es, cada día en forma más visible, mal visto por los gaullistas puros. Tanto es así, que, según parece, el General sería partidario de disolver la Asamblea Nacional y de llamar a nuevas elecciones, convencido de obtener una mayoría más segura que la tan precaria de que goza actualmente. Los últimos sondeos de la opinión pública indican, en efecto, un incremento del gaullismo y las elecciones parciales que se han producido en las últimas semanas así lo confirman.

CUNDE LA AGITAGIóN ESTUDIANTIL

\section{5 de mayo}

A pesar de la agitación estudiantil, que se ha trasladado de Nanterre a París, la vida social y diplomática sigue absolutamente normal. Para tratar de entender al "Grupo 22 de Marzo" he leído a Herbert Marcuse. Aunque no soy especialista en marxismo, me parece que el filósofo lo ha retomado por el interior. Trata de interpretar el pensamiento de Marx, no en su elaboración sino que en sus principios, para aplicarlo al mundo actual en sus últimas consecuencias. En su elaboración, llega a la conclusión que sólo hay dos grupos minoritarios, realmente revolucionarios, los habitantes de los ghettos, sobre todo de color $y$, en especial, los intelectuales, los jóvenes intelectuales, es decir los estudiantes. A mi juicio así como la revolución industrial fue dolorosa para los obreros del pasado, en la actualidad la revolución tecnológica afecta primordialmente a los intelectuales y no a la clase obrera. La diferencia principal entre la situación de ayer $y$ la de hoy es que no se trata de un problema económico o social, sino que intelectual y psicológico. Por eso, hay que 
buscar cambios mucho más profundos de las estructuras de la sociedad moderna. La dialéctica de Herbert Marcuse no busca ni la lucha de clases tradicional ni los cambios económicos, sino que sostiene que hay que cambiar violentamente todo el orden, comenzando por el hombre mismo afectado por la tecnología moderna. Herbert Marcuse sostiene que el marxismo, mediante sus ataques continuos al capitalismo, lo está obliganclo a variar y a modificarse $y$, por lo tanto, a resolver algunas de sus contradicciones $y$, como consecuencia, a vivificarse.

No sé si he entendiclo bien lo que preconiza Herbert Marcuse. En todo caso, sé que los comunistas ortodoxos rasgan sus vestiduras $y$ le acusan de pretender embalsamar a Marx. Pero, sobre todo, los estudiantes, especialmente los de Sociología, los de Filosofía, los de Ciencias Humanas y los de Letras, Io han adoptado en Francia. Hay que reconocer que descle el dadaísmo de Breton y el existencialismo de Sartre, nadie, durante muchos años, había ejercido una influencia sobre la juventud intelectual francesa. Herbert Marcuse parece haber venido a llenar este vacío.

El grupo 22 de Marzo lo ha adoptado sobre todo. Este no tiene jefe, pero sí un líder, con voz poderosa y con rara elocuencia. Es Henri Cohn-Bendit, hijo de judíos alemanes emigrados en tiempos de Hitler. Sus problemas los define así: ¿cuál es el papel de la juventud revolucionaria en los países desarrollados? ¿cuál es la función social de la Universidad? ¿cómo destruir mejor a la burguesía en el poder? ¿cómo evitar el neo-colonialismo y la opresión de los países subdesarrollados? Tales son algunas de las preguntas generosas de la juventud. De la situación actual culpan a la Universidad. "Los estudiantes -dicen- son los futuros dirigentes de una sociedad podrida, los futuros explotadores, los futuros perros guardianes. de la sociedad burguesa y de sus parásitos".

La conclusión a la que llegan es clara. La Universidad está fundada en los exámenes, en la jerarquía social y profesional, en los diplomas. Por eso hay que establecer el boycott de los exámenes. El sabotaje de ellos paralizará a la Universidad burguesa e injusta.

Existe entre los jóvenes un temor real y atrayente de ser absorbidos por la injusticia a medida que transcurran los años. Ello les lleva a prolongar el período estudiantil, el único en que reina la sinceridad, antes que el capitalismo, a la antigua o a la moderna, los liquide y los obligue a desempeñar labores tan "repugnantes" como el estudio de los mercaclos o la vigilancia de máquinas electrónicas.

Otra objeción contra el actual sistema de estudios: la Universidad es paternalista. La relación entre profesor y alumno es la de 
ESTUDIOS INTERNACIONALES

padre e hijo. El sistema de enseñanza actual ha reemplazado a la dominación del pater familiae y sólo conduce a formar individuos resignados, funcionarios pasivos.

Para destruir la Universidad, la agitación permanente es de rigor. $Y$ el grupo 22 de Marzo ha comenzado a aplicarla. De Nanterre pasó a París. El grave error del Rector de la Sorbonne fue llamar a la Policía para restablecer el orden perturbado por una lucha cuerpo a cuerpo en los patios entre los llamados "rabiosos" del 22 de Marzo y el grupo Occidente. Ha provocado así los más violentos encuentros entre estudiantes y fuerzas del orden de que haya memoria entre los últimos años.

Lo curioso es que el grupo relativamente pequeño de los "rabiosos" ha encontrado un eco que jamás tuvieron los partidos políticos, inclusive el comunista. Ello se debe, a mi juicio, a la solidaridad estudiantil frente a la actitud realmente violenta $y$, a menudo brutal, de la policía. También a que la gran mayoría de los estudiantes franceses no están politizados y miran con simpatía, por tanto, a un grupo inconexo que no se deja influenciar por los partidos tradicionales. Hay que recordar que fuera de los grupos extremistas de la izquierda, incluyendo al Partido Comunista y al P.S.U., sólo existe una juventud organizada en la extrema derecha, el grupo llamado Occidente. No hay que olvidar tampoco cierto afán de destrucción de los jóvenes que los lleva a solidarizar con los partidarios de la anarquía. Lo cierto es que en los últimos días, se han juntado más de 10.000 manifestantes para combatir en las calles a las fuerzas del orden. No es mucho si se le compara con los 130.000 estudiantes universitarios existentes en París y en sus alrededores. Pero representa una fuerza viva, emotiva, valiente y nada despreciable en su calidad.

Debo señalar que algunas Facultades como Medicina, Ingeniería, Agronomía no se han mezclado para nada en el movimiento estudiantil y siguen sus labores normalmente.

La UNEE (Unión Nacional de Estudiantes Franceses) equivalente a nuestra Federación de Estudiantes, no ha podido quedar al margen del movimiento general. Frente al cierre de la Sorbonne, frente a las brutalidades de la Policía, se ha visto, a regañadientes, obligada a declarar su solidaridad con los "rabiosos", a pesar que estos la encuentran anacrónica. El Partido Comunista ha tomado una actitud violenta, en cambio, en contra de los estudiantes después de haber pretendido dirigir y aprovechar en su favor el movimiento. Ello sucedió luego que un diputado de ese Partido fue obligado a huir por una ventana en la Universidad de Nanterre, expulsado por los estudiantes. Ahora los "rabiosos" son calificados 
por L'Humanitéb de "aventureros izquierdizantes, fraccionistas, trotzkistas, que hacen el juego del Gobierno".

A los otros líderes de izquierda no les ha ido mejor que al diputado comunista. El profesor Laurent Schwartz, sostenedor de cuanto movimiento intelectual anti-imperialista se ha producido en Francia últimamente, anti-estadounidense y miembro del Tribunal Russell, fue violentamente interrumpido en una arenga a los estudiantes; por viejo y por representar a la actual Universidad. La ironía, la falta de respeto, la desconsideración por todas las figuras cumbres, por avanzadas que sean, son características de los "rabiosos". Uno de ellos se negó a declarar en el Tribunal de Disciplina Universitario, riéndose en sus caras de los profesores. Otro tanto ha sucedido en los tribunales de Justicia que han juzgado a algunos revoltosos sorprendidos en flagrante delito.

El Gobierno ha procedido, con máxima energía; pero no ha podido doblegar hasta hoy a los "rabiosos" y a sus partidarios. Con la exclusión de sus armas de fuego, ha empleado todos los medios físicos de represión, en forma brutal, sin conseguir dominar la situación. Los tribunales han aplicado penas muy severas, dos y tres me-: ses de cárcel, a los estudiantes que han sido encontrados con armas; improvisadas y acusados de atentado a la autoridad.

Los profesores de izquierda no quieren estar con el Gobierno y atacan también a la Universidad, aunque formen parte de ella; pero no por eso se han hecho más simpáticos, aunque hayan adherido a la huelga general estudiantil.

El Ministerio de Educación busca el diálogo y lo ha declarado públicamente. Pero no encuentra con quien dialogar puesto que, por principio, los "rabiosos" lo rechazan.

\section{7. de mayo}

El General Charles de Gaulle ha declarado recién que mantendrá el orden; pero ha reconocido que la Universidad debe renovarse y que es muy grave que los jóvenes no encuentren empleos cuando terminan sus estudios universitarios. El Gobierno, manifiestamente sorprendido por los acontecimientos, no atina y busca desesperadamente, aunque tarde, a comprender lo que quiere la juventud.

Las batallas campales de ayer entre la Policía, exageradamente brutal en su represión, y los estudiantes, se han desarrollado durante 14 horas, a vista y paciencia de la clase obrera, totalmente ajena a los movimientos de la intelligentsia. El número de heridos. alcanzó ayer a 860 , algunos de gravedad.

${ }^{\circledR}$ Organo oficial del Partido Comunista francés. 
- Me han informado hoy que existen conversaciones entre el Gobierno y la Federación de Estudiantes, que no desea verse arrastrada a situaciones sin salida por los "rabiosos". Es probable que el Gobierno disponga la reapertura de la Sorbonne y de la Facultad de Nanterre y ordene la desocupación de los locales por los CRS (Compañías Republicanas de Seguridad).

A medida que la agitación va en aumento, el Partido Comunista ha ido variando en su actitud. Al comienzo, el 4 de mayo, trató a los estudiantes extremistas, entre otros calificativos de "irresponsables" y los acusó de "provocadores". Ahora está acusando a la Policía por sus métodos represivos y llamando a los trabajadores y a todos los demócratas a manifestar contra la represión gaullista. Pero.Moscú, debido a la distancia, sigue atrasada y hoy Izvestia y Pravda afirman todavía que los desmanes últimos son el resultado de la aventura preparada por grupúsculos poco numerosos pero gritones, incluidos los "maoístas" que no llevan el libro rojo sino "garrotes". Además informan que los dirigentes de la huelga son "un puñado de izquierdizantes que impiden a sus camaradas estudiar y preparar sus exámenes"

\section{ISTUDIANTES Y OBREROS}

\section{4 de mayo}

Los acontecimientos se precipitan, aunque la vida normal no ha sidó aún afectada. A pesar de las declaraciones muy conciliadoras de Georges Pompidou del sábado 11 , los estudiantes se negaron a suspender la gran manifestación programada para ayer. Tampoco las tres grandes centrales sindicales (comunista, socialista' y. ex cristiana), que visiblemente están apoyando a los estudiantes aunque con fines reivindicacionistas propios, suspendieron la huelga general decretada para el mismo día.

Esta última no parece haber tenido los caracteres que podía preverse. Los transportes urbanos y ferrocarriles han sido afectados sólo en un cincuenta por ciento; los servicios públicos, en cuanto a empleados, no tuvieron más de un diez por ciento de huelguistas y, en cuanto a obreros, la cifra no pasó de un $40 \%$, con excepción de los correos que paralizaron totalmente. Los hospitales funcionaron normalmente. En el sector industrial el porcentaje de obreros adherentes al paro fue muy variable, pero muy inferior al obtenido en huelgas propiamente profèsionales. Indudablemente, la clase obrera no se ha sentido interpretada por los estudiantes. 
En cambio el desfile de estudiantes, profesores y obreros celebrado en París fue realmente impresionante: Las cifras, como siempre, varían: doscientas mil personas, según las autoridades; cerca de.un millón, según los organizadores. En todo caso, la manifestación fue de la más grande que me haya tocado presenciar y duró cinco horas. El Gobierno había retirado a la Policía y el orden fue asegurado por los propios obreros y estudiantes, sin que se produjeran incidentes de importancia. Los únicos, y que tuvieron carácter meramente verbal, opusieron los estudiantes a los obreros y los primeros, a las organizaciones políticas de Oposición que trataban de sacar un partido de las gravísimas manifestaciones de los últimos días. Es evidente el deseo de los jóvenes, que han combatido durante una semana, de no dejarse explotar por los sindicatos de trabajadores que les han prestado un apoyo bien tardío y, menos aún, por los políticos profesionales. Se ve también que los obreros jóvenes tienen una tendencia a seguir preferentemente a los estudiantes que a sus líderes de siempre. El carácter demasiado pacífico que el Partido Comunista, especialmente, consiguió darle a la manifestación disgustó visiblemente a los "rabiosos" miembros del grupo 22 de Nrarzo que hicieron grupo aparte clurante el desfile y, sobre todo, al término del mismo. Otros sintomas interesantes: los gritos y los carteles están dirigidos contra el General Chạrles de Gaulle, los Ministros del Interior y de Educación y contra la Policía, pero no contra el Primer Ministro Georges Pompidou. La presencia en el desfile de François Mitterand, no provocó entusiasmo alguno: la de Guy Mollet, el jefe socialista, fue objeto de sostenidas pifias. Iil único político que logró algunos aplausos fue Pierre Mendes-France, confirmándose asi su popularidad entre la juventud.

La policía estuvo ausente del recorrido y se limitó a cerrar con sus camiones y fuerzas importantes todos los puentes de acceso a la ribera derecha del Sena donde un grupo de estudiantes del grúpo Occidente participó en un acto de desagravio àl Soldado Desconocido e hizo, a su vez, un desfile que terminó con la arriada de la bandera china en la Embajada que en esa zona de París mantiene el Gobierno de Pekín.

\section{5 de mayo}

Ayer los estudiantes tomaron posesión de la Sorbonne, tal como lo habían hecho dos días antes en la Facultad de Nanterre. No hubo tampoco incidentes, ya: que el Gobierno decretó su reapertura y rètiró las fuerzas policiales. El venerable edificio fue rápidamente decorado como para una Kermesse, con diarios murales a lo "chino". 
y con instalación cle orquestás de jazz en los patios y salas de clase. Lo mismo ha sucedido en Montpellier, Grenoble, Rennes, Burdeos, Lille y Nantes.

Las clases siguen suspendidas porque los estudiantes no quieren normalizar la situación. Según las declaraciones de los principales líderes estudiantiles, hay que crear "comités de acción" para estudiar las próximas medidas destinadas a suprimir la universidad burguesa. Algunos quieren establecer lo que llaman la "democracia directa" y colocar a las autoridades ante el hecho consumado. Pero la mayoría no sabe bien lo que quiere, salvo, como ellos dicen, "desorbonizar" la Sorbonne.

La verdad es que esta antigua y venerable mansión está necesitando en su estructura interna el mismo remozamiento que André Malraux le ha impuesto a su fachada. Prácticamente, desde los tiempos de Napoleón, se ha mantenido incólume y ni la Tercera República ni la Liberación lograron atentar contra su manera de vivir. Víctima de una centralización excesiva, se ha conservado rígida e inerte. Los profesores titulares, casi propietarios de sus cátedras, no hacen nada por renovarlas ni por renovarse. Todas las tentativas para lograr una autonomía interna se han estrellado contra los intereses creados y muchos de los profesores que ahora, por temor 0 por izquierdismo, se han colocado junto a los estudiantes, han sido hasta ayer los más fervorosos particlarios de un conservantismo que defiende sus privilégios. La cogestión con participación estudiantil es, en Francia, todavía un mito.

Todo ello, al fin y no para mal, a mi parecer, ha hecho crisis violenta. El problema va a consistir en la manera, en la profundidad y en la rapidez de las reformas. ¿Serán hechas con ponderación o habrán de triunfar las tesis extremistas de los estudiantes que quieren que los cursos sean discutidos y criticados por los alumnos, que estos intervengan en el nombramiento de los profesores y que se cambie el sistema de exámenes; o que desean, como los "rabiosos", que primero se destruya la Universidad para destruir así el régimen capitalista? Difícil es saber si el Gobierno tendrá que inclinarse ante los reformistas o ante los revolucionarios. Pero, lo que es un hecho es que la Universidad francesa, tal como ha funcionado desde hace ciento cincuenta años, dejó de existir en Francia.

El problema principal va a consistir en dialogar con los estudiantes. El Gobierno y las autoridades están dispuestos a este indispensable diálogo; pero los estudiantes son de tendencias tan diferentes que no será fácil iniciarlo y llevarlo a fines constructivos.

Veamos ahora las consecuencias políticas. Manifiestamente, el Gobierno se ha debilitado. No supo ceder a tiempo. Ahora trata 
inteligentemente de recuperar sus errores y ha cumplido sus promesas. Ha abierto las Universidades, ha retirado a la Policía, ha impuesto en libertad a los detenidos y ha obtenido que los Tribunales de Apelación dejen también libres a los condenados, en espera de una ley de amnistía. Pero esto no ayuda necesariamente a la Oposición; la desconfianza de la Juventud abarca a todos los políticos, Gobierno y Oposición en conjunto, Partido Comunista inclusive. Todos ellos se equivocaron y ninguno fue capaz de apreciar el volumen del descontento estudiantil y la profundidad de la solidaridad entre la Juventud. En realidad, por primera vez en Francia, los autores de un motín son los verdaderos vencedores. $\mathrm{La}$ juventud es la única que ha triunfado. Alguien -ya no sé quién (tanto es lo que he leído y oído últimamente) - había anunciado que la ola de la Juventud nacida en la post-guerra estaba ad portas. Pues parece que las ha derribado en forma violenta. Ello no es saludable para la Democracia.

La afirmación anterior no significa que crea en un cambio violento de las instituciones francesas por el momento. A lo sumo es posible que en los próximos días el General reemplace a uno o dos Ministros que no respondieron a su confianza (aunque es bien probable también que no lo haga de inmediato para no aparentar debilidad). No creo que la moción de desconfianza presentada por la Oposición en el Parlamento logre éxito, porque sería ilógico que aquella sacara provecho de un movimiento espontáneo y que se desarrolló en forma marginal a la política. Pero creo que los acontecimientos que hemos vivido en los últimos diez días están demostrando que las bases de la sociedad francesa están seriamente amenazadas y que este país, tanto o más que otros, necesita renovarse.

El General Charles de Gaulle ha partido entretanto a Rumania, ha delegado sus poderes en Georges Pompidou y ha anunciado que se dirigirá al país por radio y televisión, a su regreso. Muy interesantes serán sus palabras.

El despertar ha siclo violento. Tanto el Gobierno como la Oposición vivían en el mejor de los mundos, contentos en el fondo de que Francia amasara oro, adelantara en la técnica y mostrara la solidez de sus instituciones burguesas.

El propio Partido Comunista mantenía sus reivindicaciones, pero se acomodaba al orden y a la legalidad y no tenía intenciones de provocar problemas que pudieran complicar sus relaciones con los demás Partidos de Izquierda. Jugaba el juego democrático sinceramente. Resulta que ahora, sus peores enemigos, los trotskistas, los anarquistas y los "marcusianos" han entrado en acción violenta y lo han colocado en una situación difícil. 
Pero es evidente que ni la riqueza, ni el adelanto técnico, ni las instituciones burguesas, ni el juego democrático, satisfacen a una juventud confundida, pero generosa, desconcertada, pero pletórica de Justicia en sus elucubraciones y, sobre todo, que no encuentra' ubicación en partidos políticos, con la excepción del comunista, carentes de atracción y de ideología.

Veremos lo que sucede. El Gobierno ha sido sabio en dejar en libertad a los jóvenes y en no ponerles cortapisas. Espera pacientemente que se desprestigien y se agoten en divagaciones sin fin. Pero lo sucedido en estos días tiene mucho de irreversible en lo que a la vida universitaria se refiere.

POLÍTICA $x$ ESTUDIANTES

\section{6 de mayo}

Anteayer asistí al debate político en la Asamblea Nacional. Sólo hoy puedo resumir mis impresiones, pues no me alcanza el tiempo para atender a mis compatriotas atemorizados, informarme, tener un criterio propio y, al mismo tiempo, mantener al tanto al Ministerio en Santiago de lo que aquí sucede. Georges Pompidou pronunció un importante discurso en un debate que adquirió caracteres violentos. Además de Primer Ministro, reemplaza a Charles de Gaulle quien, a pesar de la situación interna, ha partido a Rumania en visita oficial. Esto no hubiera sucedido en otro país; pero el: General no quiso, por una parte, dejar sin efecto un compromiso internacional -lo que es muy propio de él-y, por otra, dar la impresión que la situación interna era caótica, como lo está siendo en realidad. Las ideas generales desarrolladas por Georges Pompidou fueron las siguientes: en primer lugar, el orden público debe ser mantenido: "si no es extraño que un cierto número de jóvenes declaren su desacuerdo con la sociedad, no es admisible que pretendan imponer la ley en una sociedad de la que reniegan...". Reconoció también que entre los estudiantes hay anarquistas "contando con medios financieros importantes y con material adecuado para los combates de calles, dependientes de una organización internacional que no sólo quiere crear la subversión en los paises occidentales, sino que también imponer el desorden en París en los momentos en que nuestra capital ha sido elegida como la sede de la paz en el Extremo Oriente". Anunció medidas contra esa "organización internacional", que evidentemente ha de ser "maoísta". Personalmente, tengo dudas sobre la veracidad de esta información. 
Reconoció, asimismo, la existencia de serias insuficiencias en el sistema educativo, especialmente en las Facultades de Letras y Ciencias Humanas, y la necesidad de asegurar el porvenir de los egresados. De allí su decisión de crear un Comité de Reflexión en que estarán representados los profesores, los estudiantes, las asociaciones de padres y "todas las familias espirituales" que propondrán las: reformas indispensables. Estas deben ir en el sentido de la autonomía universitaria y en la adaptación de los planteles de enseñanza superior a las actividades económicas y sociales del presente.

Junto con reconocer que los acontecimientos vividos en estos. últimos días no deben ser considerados como esporádicos, sino que. deben tener consecuencias útiles, no disimuló las dificultades de la empresa, para la cual la colaboración de los estudiantes es vital. "No se trata únicamente de transformar la Universidad. A través: de los estudiantes, estamos enfrentados al problema de la juventud, de su ubicación en la sociedad, de sus obligaciones y de sus derechos y aun, de su equilibrio moral". El análisis que hizo de los. problemas de la juventud actual es, a mi juicio, muy profundo e inteligente. La situación la comparó al período de "desesperación" del siglo xv cuando "se estaban desmoronando las estructuras de la Edad Media". De allí que, ya no sean ni el Gobierno, ni las instituciones, ni aun Francia, quienes estén en peligro, sino que nuestra propia civilización.

Pero, las conciliadoras palabras de Georges Pompidou en el Parlamento no han tenido el menor eco entre los estudiantes extremistas que se han apoderado de la Sorbonne y de otras Facultades. Por el contrario, en un movimiento sorpresivo, se tomaron también el Teatro del Odeón, perteneciente al Estado, sin escuchar las exhortaciones de su director Jean Louis Barrault quien, sin embargo, se ha distinguido por sus tendencias izquierdistas.

Instalados en la Sorbonne y en el Odeón, los estudiantes han aprovechado, a su manera, la libertad total que les ha dejado el Gobierno. Esta ocupación ha sido hecha en forma simpática. Ambos establecimientos, en los que se permite entrar al público que desea informarse, han tomado el aspecto de una kermesse o, mejor todavía, de. un happening. Todo se ha hecho en forma amable y en el gran patio. de la vieja Universidad se han instalado puestos en que venden su propaganda, lado a lado "castristas", "trotzkistas", "anarquistas", "maoístas" y comunistas ortodoxos. Allí se discute interminablemente en los patios y en las salas, transformadas en sedes de "comités. de acción" permanentes, bajo las banderas rojas y negras.

Pero estos aspectos folklóricos de la ocupación, están chocando a la opinión pública que poco o nada entiende de la "revolución. 
cultural". Las apariencias revolucionarias, el vocabulario empleado, la amenaza de terminar con la burguesía atemorizan al segundo pueblo más burgués de Europa, después seguramente del suizo. Síntoma de cultura de este país: todas las discusiones entre las diferentes tendencias revolucionarias y el público asistente que no pertenece a ninguno de esos movimientos, se hace en forma tranquila, sin llegar nunca al insulto, ni menos a las vías de hecho.

Aclemás, las discusiones son largas, eternas, confusas. Al reemplazar la acción por la palabra, están perdiendo el entusiasmo y aun la solidariclad creada en las barricadas. También se está apaciguando la gran simpatía que la juventud logró cuando se produjo la represión policial. Es evidente que es muy difícil mantener durante días y días, noches y noches, el entusiasmo y la tensión de las primeras horas. La prolongación del estado de cosas actual va a llevar al movimiento juvenil a lo que aquí llaman el "pourrissement" (pudrición).

Por último, al pretender suprimir los exámenes, los "rabiosos" están provocando una reacción de ciertos e importantes sectores estudiantiles desorganizados aún, pero que no desean perder un año de estudio y quieren, a pesar de todo, tener el tan criticado diploma. Los padres de familia, que tienen todas sus vacaciones organizadas, ven con espanto, por su parte, que el desorden universitario actual les va a complicar sus programas de veraneo, para el cual vienen preparándose descle el año pasado.

Este peligro lo conocen los dirigentes estudiantiles $\mathrm{Su}$ gran temor es que el Gobierno, al darles entera libertad, está ganando un tiempo que trabaja en su favor. Contrariamente a Aníbal, escribe un periodista de izquierda, que no sabía aprovechar sus triunfos, Georges Pompidou podría sacar provecho de su derrota. Si las cosas continúan en el terreno estudiantil como van, en algunos días puede conseguir por la inercia lo que no pudo obtener mediante la represión policial.

De allí que los dirigentess extremistas decidieran, para mantener el entusiasmo, la toma del Teatro del Odeón y acogieran con gran entusiasmo las ocupaciones de fábricas efectuadas por solidaridad y dirigidas, en toclos los casos, por elementos obreros jóvenes.

\section{7 cle mayo}

Ayer en la tarde fui a visitar a M. Gallichon, actual Presidente de Air France y, hasta hace poco, Jefe del Gabinete del General Charles de Gaulle, con quien tengo mucha confianza. Lo noté preocupadísimo y me proporcionó informaciones útiles sobre el ambien- 
te en el gobierno. Desea el pronto regreso del General de Rumania y. que tome en sus manos el poder que se está degradando. Es muy difícil informarse. No se puede ahora visitar a los Ministros, los funcionarios están mudos y amedrentados, mis colegas del Cuerpo Diplomático, asustados y sin comprender acontecimientos que los han tomado desprevenidos. He sabido, sin embargo, que la situación anoche estuvo realmente caótica. Tanto que el Gobierno, que había permanecido mudo después del debate en la Asamblea Nacional, se decidió a hablar. Contra la opinión de Georges Pompidou, la mayoría del Ministerio le obligó a hablar por la televisión para asegurar; en frases cortísimas, que mantendría el orden, pero que necesitaba del apoyo de todos los franceses contra la anarquía que amenaza al país. Ayer tarde, en efecto, en forma absolutamente imprevista y contra la voluntad de los dirigentes sindicales, varias fábricas fueron paralizadas y ocupadas por los obreros que desean manifestar su. solidaridad con los estudiantes. Lo que es más grave, la Policía, desorientada por la inactividad y la pasividad de Georges Pompidou, manifestó su desagrado y aprovechó la oportunidad para plantear reivindicaciones económicas. Anoche el Gobierno esturo realmente a punto de caer, a menos de utilizar al ejército para mantener el orden, lo cual habría sido demasiado drástico y peligroso. ¿Quién le iba a quitar después el control de la situación? Tan peligrosa: fue la situación anoche que hoy el Partido Comunista reaccionó: para evitar que se escape de las manos de la poderosa Confederación. General del Trabajo la dirección laboral. Creo, sin temor a exagerar, que anoche estuvimos a punto de que se creara un vacío de poder: y se estableciese una nueva "Comuna", del tipo de la de 1870.

\section{EL PARTIDO COMUNISTA Y LOS ESTUDIANTES}

\section{8 de mayo}

La vida social y diplomática se ha paralizado. En plena temporada social, se ha dado contraorden a todas las recepciones y manifestaciones. Entre tanto, el partido comunista ha recuperado, mediante un golpe realmente maestro, el control de los movimientos huelguísticos. La Confederación General del Trabajo, seguida por la Confederación de Trabajadores Democráticos (separada de la cristiana), han ordenado una serie de huelgas en París y provincias con reivindicaciones de tipo esencialmente económico, separándolas de las provocadas por trotzkistas, anarquistas y maoístas, que apoyaban el movimiento estudiantil. Esta tarde había tres millones de obreros, 
con ocupación de fábricas. Mañana puede haber seis o siete millo-. nes. Pero. ahora bajo el control de las grandes centrales sindicales, ya que "Fuerza Obrera", socialista, se ha acoplado también al mo-. vimiento.

La frase más sintomática de la reacción comunista sea tal vez la que escribió René Andrieux en L'Frumanité de hoy: "La clase obrera es mayor de edad. No necesita tutores". El Partido Comunista, calificó en un comienzo a los estudiantes de "aventuristas" de "grupúsculos", de "falsos revolucionarios", decidió, ante la amplitud del movimiento estudiantil, apoyarlo y "recuperarlo", seguido con tres. días de atraso en sus apreciaciones por la prensa soviética. EI Partido Comunista teme, y no sin razón, que los estudiantes lancen. a la clase obrera en una aventura que podría desembocar en una: dictadura militar, aplaudida por la opinión pública, temerosa del desorden. Por eso, para el Partido, Henri Cohn-Bendit y sus "rabiosos", constituyen el "enemigo público número uno". El secretario General de la CGT llegó a decir en una entrevista que no. sabía quién era...

Por último el Partido Comunista teme el contagio. Los "rabiosos" son valientes, generosos, inteligentes, poseedores de una terrible dialéctica. Si toman contacto con los obreros, pueden hacer germinar las dudas en las mentes de las bases. De allí que haya prohibido, seguido por las otras centrales, todo contacto verbal entre: huelguistas obreros y estudiantes. Cuando estos últimos hicieron. una larga marcha para entrevistarse con los obreros de Boulogne. Billancourt, encontraron las puertas de las fábricas cerradas y tuvieron que regresar a la Sorbonne hambrientos y cansados.

He preguntado por qué las centrales CFDT y F.O. han seguido. la línea de la CGT. Se me ha explicado que no desean tampoco ser llevados a la aventura por los estudiantes y que desean el mantenimiento del régimen democrático; pero que, además, desean aprovechar las dudas que entre Ios obreros comunistas, sobre todo entre los jóvenes, pueda presentar la actitud del Partido Comunista.

Tenemos el caso extrañísimo, pues, de huelgas con una amplitud sin precedentes (no hablo de paro general porque no ha sido decretado), simultáneas con la huelga estudiantil, consecuencias de esta última, pero sin relación con ella. Sobre todo de huelgas llevadas. en perfecto orden y con exclusivas reivindicaciones económicas. Así, mientras los estudiantes pretenden cambiar la sociedad y texminar con el orden burgués, los obreros tratan de sacar las mayores. ventajas de tal orden y de tal sociedad. No puedo dejar de recordar las afirmaciones de Herbert Marcuse, según las cuales la juventud, sobre todo la juventud intelectual, es la víctima del avance tec- 
nológico y la clase obrera no es ya la explotada. Entre parénitesis, creo que esta afirmación se aplica exclusivamente a los países desarrollados y no a aquellos que no han alcanzado ese estado.

Se explica la actitud del Partido Comunista, porque aquí, como -en otras partes, parece haberse aburguesado e instalado en la sociedad capitalista. En todo caso, ha jugado, en momentos de gran peligro para Francia, el juego democrático.

A mi juicio, salvo que los estudiantes hagan algo, y estoy por creer que han perdido ya la oportunidad, van a ser dominados por la inercia a que los ha condenado el Gobierno y por la lucha sorda -que le presenta el Partido Comunista. Ambos se han juntado espontáneamente para liquiclar un germen considerado dañino por distintos motivos.

Queda ahora el otro enfrentamiento, más peligroso para el Gobierno, pero más conocido y que ya tiene precedentes. ¿Cómo va a solucionar la ola de huelgas que tiene paralizado al país? Si cede a las reivindicaciones, adiós al Mercado Común que debe entrar en vigencia total dentro de pocas semanas, porque Francia no podrá competir. Si no cede, ¿cómo reduicir a seis o siete millones de trabajadores?

Creo que mientras el Partido Comunista siga en su juego democrático, el problema va a ser resuelto en el Parlamento, donde el martes y miércoles se discutirá la moción de censura presentada por toda la Oposición sobre la política económica, social y educacional del Gobierno. La votación será muy estrecha; la solución la darán los diputados del centro y los independientes. ¿Se atreverán a producir. una crisis de gobierno en las actuales circunstancias?

¿Ampliará el General la base cle su gabinete para dar satisfacción a una parte de la opinión pública que no es gaullista, pero que está asustada? El General no lo ha dicho. Regresa hoy de Rumania, anticipando su viaje, y permanece mudo. Se creyó que adelantaría su discurso anunciado para el clía 24, pero parece que no. lo. hará:

El sabe tantas cosas, sabe también la fuerza del silencio y cuánto desconcierto causa entre sus adversarios.

\section{EL RÉGINEN EN PELIGRO}

El porvenir no sólo dèl Ministerio, sino que del régimen eștá en peligro. La Izquierda espera su oportunidad, aprovechándose dẹ un movimiento estudiantil que sin embargo la condena.

En estos momentos, la Ville Lumière presenta un espectáculo bastante novedoso, sin medios de transporte, aislada del exterior, con amenaza de falta de alimentación, de corriente eléctrica $y_{2}$ de gas, 
con los servicios de aseo paralizados, con el Barrio Latino en poder de los estudiantes, con la Policía concentrada en lugares estratégicos. Nos queda aún el teléfono y la radio, ya que los periódicos. aparecen cuando pueden, para mantener el contacto con los acontecimientos. A una huelga de correos parcial, durante la semana, se ha agregado ahora la parálisis total de este servicio. Los compatriotas me quitan mucho tiempo. Todos quieren hablar con el Embajador para pedir consejos. Algunos están presa del pánico al no. poder salir ya de París debido a la paralización total de los aeropuertos, ferrocarriles y transportes colectivos. A los que "turistean", les aconsejo que busquen manera de ir a hacerlo a algún país vecino.

\section{9 de mayo}

En estos momentos hay huelga de ferrocarriles, industria automovilística, siderurgia, textiles, astilleros, usinas eléctricas, compañías aéreas, con ocupación de fábricas. El aeropuerto de Orly quedó paralizado y no puedo ni enviar ni recibir valijas diplomáticas.

Ante la amplitud cle las huelgas de tipo económico, el movimiento estudiantil parece estar perdiendo actualidad, lo que puede llevar a los "rabiosos" a extremar acciones violentas para reconquistar su prioridad.

El teletipo con Santiago no funciona. Pido a través de Víctor Santa Cruz ${ }^{7}$, que Santiago me llame todos los días porque, misterio de estos aparatos, recibo llamadas pero no puedo hacerlas.

Tengo una información de primera mano, según la cual el Gobierno hā dado seguridades a la policía y a los CRS que reprimirá con firmeza cualquier acción de los estudiantes extremistas, con lo cual ha recuperado su fidelidad, evitando así tener que acudir a las Fuerzas Armadas para mantener el orden.

\section{0 de mayo}

Estoy totalmente aislado de Chile. Felizmente, funciona normalmente el teléfono automático con Londres y Alemania, así es que puedo informar a Chile por esos conductos, especialmente a través del Consulado General de Frankfurt. La huelga se ha extendido ahora a la totalidad de la locomoción colectiva, a los correos y telégrafos y se anuncia un paro bancario. Existen serios problemas en

${ }^{7}$ Embajador de Chile en Londres. 
materia de alimentación y para obtener bencina. El gas y la electricidad están ocupados por los obreros, quienes cortan a ciertas horas los servicios; pero el problema es soportable. Mañana y pasado se tratará en la Asamblea Nacional el voto de censura contra el Gobierno. En caso de ser aprobado, es posible -me informan- que Charles de Gaulle disuelva el Parlamento. Mi impresión, sin embargo, es hoy que el peligro mayor para la estabilidad del régimen ha pasado, en buena parte gracias a la actitud del Partido Comunista que ha logrado controlar a los sindicatos y evitar la continuación del desorden. Existe también un evidente cambio en la opinión pública, muy asustada, y que está reaccionando más contra los estudiantes que contra los obreros.

\section{2 de mayo}

Con la extensión de la huelga a la totalidad de los servicios públicos, los bancos, los hospitales, el cierre del comercio y la ocupación de algunos hoteles por el personal. No falta, sin embargo, la alimentación esencial; pero están racionados el azúcar y la harina. No hay bencina y esto dificulta aún más mi búsqueda de información. Como los servicios de aseo están en huelga descle hace días, se ha acumulado gran cantidad de basuras y, además de la pestilencia del olor, sobre todo en las callejuelas del Barrio Latino, ha aparecido una nueva calamidad, la invasión de una plaga de ratas.

Ayer y hoy, en sesiones matinales, diurnas y nocturnas, la Asamblea Nacional discutió la moción de censura contra el Gobierno, presentada por la Federación y el Particlo Comunista. Los debates fueron dramáticos. Asistí la tarde entera, ayer. La moción necesitaba contar con 244 votos. Obtuvo 233.

El triunfo del Gobierno fue pobre y no ha salido favorecido. En efecto, si bien contó con el apoyo de los "giscardianos", éste fue hecho con tales reservas que no significa el cheque en blanco que Georges Pompidou deseaba. Casi la totalidad de los diputados del Centro Demócrata votó en contra, con lo cual la sustentación del Gobierno no se amplía, a pesar de harto necesitarlo. Sólo contó con el apoyo directo de algunos independientes y dos o tres diputados del Centro Demócrata, los más derechistas, que se negaron a votar la censura por temor al caos. Por último, se produjeron en las filas del Gobierno dos deserciones. El diputado gaullista de izquierda, M. Capitant, de gran prestigio, prefirió renunciar a su cargo de diputado antes de votar la confianza al Gobierno. $Y$ otro gaullista de nota, M. Edgar Pisani, que fue durante seis años Ministro del General, votó en contra del Gobierno anunciando que renunciaría en 
seguida a su cargo. Estas dos actitudes tuvieron influencia en la: posición del Centro Demócrata. Aun cuando muchos de sus miembros en un comienzo parecían decididos a negarse a votar la censura; y aún estaban dispuestos a ingresar a un nuevo Ministerio bajo Georges Pompidou, la votaron finalmente, ante la actitud inflexible del Primer Ministro que no dio seguridades ni de ampliar: su base ni de realizar una política diferente en lo económico $y$, sobre todo, en lo social.

Todo ello ha contribuido a disminuir el prestigio del Ministerio. Hubiera necesitado, ante la gravedad de las circunstancias, una mayoría importante. No la obtuvo y si se salvó fue, indudablemente, por el miedo al vacio, a la aventura. Este miedo influyó más que el temor a la posibilidad de una disolución de la Asamblea, claramente esgrimida por el Gobierno. En resumen, si Georges Pompiclou hubiera pedido un voto de confianza, hubiera sido vencido. Prefirió contentarse con el rechazo de la moción de censura que le permitió gozar del apoyo de algunos enemigos, como el diputado de, ultra-derecha Frederic Dupont, el vencedor de Fenri Couve de Murville en las elecciones, que prefieren a Georges Pompidou a un Gobierno de izquierda.

Gon todo, a mi juicio, el Gobierno fue salvado sobre todo, a pesar de las-violentas declaraciones en contra, por la actitud-de la Confecleración General del Trabajo, de ciega obediencia comunista. Dicha 'organización sinclical, la más importante de todas, declaró; antes de la votación en la Asamblea Nacional, que estaba dispuesta a entrar en negociaciones con el Gobierno. Pero fue aún más lejos. Anunció que sus reivindicaciones serían mantenidas cualquiera que fuese el Gobierno que sé formase. ¿Para qué entonces derribar a Georges Pompidou si' un gobierno de izquierda; cuya formación podría haber tenido la yentaja de terminar con las huelgas, se hubiese visto abocado a la misma situación existente?

Ahora se trata de saber si el General Charles de Gaulle va a sacar conclusiones acertadas de esta gravísima crisis en que se ha visto envuelta Francia en forma tan espontánea como súbita. Mi impresión es que el Primer Ministro cree todavía que los métodos tradiciónales pueden solucionarla y que las negociaciones con las centrales sindicales, llevadas con paciencia, pueden hacer retornar la paz social, en este país. Pienso en forma distinta porque los obreros se han dado perfectamente bien cuenta de su inmenso poder $y$, por lo tanto, las negociaciones van a ser mucho más difíciles de lo que el Gobierno piensa. Además, los tiempos han cambiado y también hay que variar en forma radical la manera de enfrentar los problemas. No está pasando Francia por una crisis cualquiera. Es 
la primera manifestación del término de un sistema de vida en uno de los países más burgueses de Europa. Si no se parte de esta premisa, las soluciones van a ser meramente transitorias. Y no creo que Georges Pompiclou aprecie los acontecimientos en lo que son en realidad.

Tengo confianza, sin embargo, en el General. Mañana, finalmente, oiremos su voz. La Esfinge va a abandonar su silencio. ¿Qué dirá el Oráculo? Tratándose de un hombre de su inteligencia y de su visión, me atrevo a esperar que su interpretación de los hechos sea lo suficientemente exacta y elevada. Además, conozco su pensamien* to íntimo en materia social, mucho más avanzado que el de sus colaboradores Por eso, como la totalidad de los franceses que estarán mañana instalados frente a la televisión (dirigida ahora por los periodistas independientes que se la "tomaron"), tengo todavía fe.

En su caso, insisto en el valor psicológico de su silencio. Ha querido ver claro antes de dirigirse al país. Ha dejado gastarse y desgastarse a sus Ministros. En los momentos más difíciles de la historia de Francia de la post-guerra (mucho más difíciles que los que afrontó cuando el problema de Argelia) ha mantenido su estatura. Ojalá no baje mañana de su pedestal. Lo deseo por este país. Lo deseo por el mundo occidental porque tengo el convencimiento que lo que aquí pasa es un reflejo de lo que sucede en esta región y que las consecuencias de lo sucedido van a tener repercusión fuera de este país. Lo deseo también por Chile y su Gobierno, hacia el cual el General ha demostrado una amistad sincera descle más de tres años.

¿Qué puede proponer el General? Debe ser algo realmente revolucionario, capaz de interesar a la masa obrera y de abrir perspectivas a la juventud. Este hombre de 77 años es capaz de hacerlo. Ya en 1948 lanzó, en un discurso famoso, sus ideas sobre la "participación". En aquella oportunidad dijo, más o menos lo siguiente:

"Hay que terminar con el sistema absurdo actual en que, mediante un salario mínimo, se proporciona un esfuerzo colectivo mínimo y con un resultado también mínimo. Hay que terminar con la oposición entre los diversos grupos de productores que envenena y paraliza la actividad. Fay que buscar la asociación entre el patrón y el obrero. Esta asociación debe existir en cada empresa entre los dirigentes, los técnicos y los obreros, quienes fijarían de común acuerdo, $y$ con un arbitraje organizado, las condiciones de trabajo y, especialmente, las remuneraciones. Éstas serían fijadas en forma tal que, desde el Presidente de la empresa hasta el último obrero, recibieran un sueldo o salario proporcional dentro de las ganancias de la empresa. Así se lograría la autoridad para quienes la dirigen, el amor del trabajo en los obreros, la capacitación profesional para todos y se terminaría la explotación de los unos por los otros". 
¿Las desarrollará ahora el General para ponerlas a tono con las necesidades actuales? Sería una buena salida que dejaría atónitos a los sindicatos que piden, en el fondo, sólo aumento de salarios, disminución de las horas de trabajo, jubilación a los 60 años y seguriclad en el empleo. Puede también hacer ingresar al Gobierno a los gaullistas de izquierda, leales a su persona y que no se sienten interesados por Georges Pompidou.

\section{3 de mayo}

Creo que la actitud del Gobierno de abandonar el Barrio Latino a la juventud en huelga ha sido muy inteligente. Las eternas discusiones dentro de la Sorbonne y del Teatro Odeón, la falta de actividad y de acción de los estudiantes que no tienen pretextos para desfiles callejeros, está produciendo el "pourrissement" (pudrición) que las autoridacles querían. Además, la huelga general ha dirigido la atención de la opinión hacia los problemas laborales, mientras los estudiantes siguen, bastante aislados ya, ensimismados en sus confrontaciones icleológicas. En vano los dirigentes "rabiosos" buscan la oportuniclad para salir de nuevo a la calle y aplicar el consejo de Marx (ver "Introducción a la crítica de la Filosofía del Derecho, de Hegel"): "No hay que dejar que los alemanes se dejen llevar ni un instante por las ilusiones y por la resignación. Hay que hacer que la opresión sea más opresiva, agregando la conciencia de la opresión. Hay que hacer la vergüenza más vergonzosa, gritándola en las calles".

Esta ocasión, gravísimo error, se la ha dado el Gobierno a los estudiantes. En efecto, aprovechando un viaje a La Haya del líder Henri Cohn-Bendit, le prohibió su reingreso a Francia. De inmediato, la Juventud encontró lo que buscaba. De nuevo ha salido a la calle, dirigida por los "rabiosos", los maoístas, los trotzkistas y los anarquistas, es decir aquellos que el Partido Comunista había dejado "pourrir" (pudrir) mediante un acuerdo tácito con el Gobierno. Anteanoche y esta noche han surgido manifestaciones y las barricadas se han levantado de nuevo.

Además, otro grave error, la Policía ha pretenclido nuevamente ocupar el Barrio Latino. El Gobierno ha cumplido así con su promesa dada a las fuerzas del orden de que reprimirian, con la brutalidad que las caracteriza, la agitación, si ello volvía a producirse.

Cuando se trata de la Juventud, los errores se pagan caro porque los resultados no son previsibles. Justamente cuando el Gobierno había restablecido, aunque débilmente, su autoridad, se ha encargado de crearse asimismo un nuevo problema, más delicado aún 
que el laboral. Mucho me temo que la situación se haya deteriorado en estas últimas horas y tal vez en forma irreparable.

Tal es la situación hoy en la noche.

Todavía espero en que Charles de Gaulle sea capaz de salvar a Francia en 1968, como lo hizo en 1940 y en 1958. Si no, mucho me lo temo, tendremos una situación caótica y contagiosa.

\section{EL ORÁCULO DESILUSIONA}

\section{4 de mayo}

Después de guardar silencio quince días, durante los cuales la elucubración central giraba alredeclor de la actitud que el Jefe del Estado podría asumir, se dirigió al país por cadena radial y televisada, que duró sólo siete minutos, en los cuales se limitó a reconocer la necesidad de efectuar cambios profundos de las estructuras económico-sociales y en la Universidad, los cuales supeditó a un referéndum que se realizará probablemente el 16 de junio próximo y que equivale a un voto de confianza del pais a su persona. Si el referéndum le es adverso, el General Charles de Gaulle dejará. el poder. Si obtiene un "apoyo masivo" llevará adelante reformas: a las cuales no se refirió y para las cuales piensa contar con la colaboración de los diversos sectores interesadós.

Todos aquellos observadores que confiábamos en una gran ofensiva del estratega que había calculado cuidadosamente el poder y la duración de su silencio, nos sentimos abiertamente desilusionados. En circunstancias que todos los franceses, hasta los propios manifestantes, quienes detuvieron sus marchas para escucharlo con radios a transistores, esperaban "Su Mensaje" y temían o confiaban, según sus puntos de vista, en un gran discurso en que demostrara su visión de estadista y propusiera soluciones concretas para las tremendas mutaciones por las que Francia atravesaba, quien les habló fue un anciano cansado y abatido, que reconoció, en siete minutos, el fracaso social, económico y universitario de las estructuras que él había mantenido invariablemente durante diez años de poder omnímodo.

Tampoco anunció ningún cambio ministerial -alternativa que la opinión pública del país esperaba como muy viable y necesariaespecialmente frente a la iniciación de las conversaciones entre los sindicatos, los empresarios y los representantes del Gobierno. 
Hoy se inician las negociaciones entre el Estado y los representantes patronales y obreros. Existe la impresión que si se accede a la totalidad de las peticiones de estos últimos, Francia irá a la ruina, a la inflación y a la devaluación del franco. Si se las rechaza, la huelga proseguirá y lo peor puede producirse. Pareciera como si el Gobierno se hubiera colocado en la posición de escoger la muerte violenta o la muerte a corto plazo.

Entre tanto, debido a su negativa de permitir el regreso de Henri Cohn-Bendit, el Gobierno ha dado la oportunidad que los "rabiosos" buscaban para ponerse de actualidad nuevamente. Las manifestaciones de anoche y especialmente las de anteanoche, fueron violentísimas y las fuerzas policiales y CRS dieron la impresión de no estar .controlando la situación.

\section{6 de mayo}

Ayer continuaron las manifestaciones estudiantiles en París y en provincias. En Lyon se produjeron incidentes extraordinariamente graves. Anoche hubo verdaderas batallas campales en París, con cerca de 500 heridos. Sin embargo, tengo la impresión que los estudiantes organizados están predominando sobre los "rabiosos" y buscan evitar enfrentamientos y desmanes que asusten a la opinión pública y al elector burgués, que debe votar el referéndum a mediados de junio.

Las negociaciones laborales prosiguen y los sindicatos se encuentran en posición de fuerza, pues la huelga general continúa. Sin embargo, tengo la impresión que no desean extremar sus peticiones, preparándose también para el referéndum y buscando no atemorizar al elector de clase media.

Lä bencina ha desaparecido y para conseguir llenar los tanques, el Cuerpo Diplomático debe enviar sus automóviles a una "cola" que hoy duró tres horas. La alimentación es suficiente, pero con gran alza de precios. El kilo de papas llegó hoy a sesenta centavos de dólar. 
EL GOBIERNO SE INCLINA

Terminaron con un acuerclo las negociaciones laborales iniciadas anteayer y presidiclas por Georges Pompidou, quien estaba asesorado por varios Ministros que en nada representan el "nuevo espíritu indispensable para resolver la huelga más completa y sustancial que ha conocido Francia desde la Segunda Guerra Mundial".

Para enfrentar a las poderosas centrales sinclicales, que gozaban de la inmensa ventaja de iniciar el diálogo durante la parálisis que ellas mismas habían provocado y negociaban en estrecha unión. estaba la Confederación del Patronato francés, temerosa y animada del mejor espíritu para evitar la ruina inmediata de la producción nacional, aun a riesgo de no poder evitarla en el futuro, ya que la competencia internacional y el Mercado Común impiden una mayor alza de costos. En el papel de árbitro está el propio Georges Pompidou, quien demostró condiciones extraordinarias de negociador y una resistencia física a toda prueba. EI Primer Ministro, en efecto, no ha dormido prácticamente desde que llegó de su viaje al Irán y a Afganistán y ha soportado con una entereza que sus propios adversarios admiran, las tremendas responsabilidades de los últimos días.

Después de veintiocho horas de difíciles y continuadas negociaciones, se llegó a un resultado ampliamente satisfactorio para las centrales sindicales. En algunas horas, lograron hacer triunfar las aspiraciones acumuladas en polvorientos legajos que habían dormido durante los últimos años. El Gobierno, deseoso de poner en marcha al país y preparar a los ciudadanos para el próximo referéndum, capituló en todos los frentes. Otro tanto se vio obligada a hacer la Confederación del Patronato.

El salario mínimo fue aumentado en $35 \%$; se establece un aumento general de salarios de $7 \%$ el 19 de junio y de $3 \%$ más octubre; el Gobierno se compromete a presentar un nuevo proyecto de ley sobre derechos sindicales en las fábricas; se acepta el prin. cipio de un aumento de las asignaciones familiares y jubilaciones; se conviene también en que los días no trabajados serán recuperados antes del fin de año, pagándose de inmediato el $50 \%$ de los salarios; se prevé una reducción paulatina de la jornada de trabajo.

Por último, el Gobierno aceptó que los decretos leyes que había dictado en materia de seguridad social y destinados a financiar este 
servicio en franco déficit, fueran estudiados por el Parlamento, previéndose algunas modificaciones.

En otras palabras, todas las peticiones de las centrales sindicales fueron aceptadas.

\section{8 de mayo}

El país respiró ayer por la mañana porque creyó ver renacer la normalidad, aun cuando los industriales y los economistas han previsto las terribles consecuencias en un plazo relativamente corto: la inflación y la desvalorización del franco como medio de competir en los mercados internacionales y de compensar el aumento de los costos de producción.

Pero, este respiro fue de corta duración. En efecto, las centrales sindicales, aunque satisfechas de los resultados alcanzados, hicieron la reserva de que las "bases" debieran ser previamente consultadas. Influidas muchas de éstas por la facilidad con que habían capitulado el patronato y el Gobierno, y también por la indudable propaganda de los elementos extremistas que se habían introducido en las usinas ocupadas, desautorizaron a las centrales sindicales y decidieron continuar la huelga, insistiendo especialmente en obtener el pago total e inmediato de los días no trabajados; en rechazar el aumento de salarios por simples porcentajes, exigiendo en cambio que éste se haga según las categorías y favorezca especialmente a las más atrasadas; en conseguir un salario mínimo industrial de 1.000 francos mensuales (US\$ 200.-), la jubilación a los 60 años para Ios hombres y 55 para las mujeres; y la vigencia inmediata de la jornada de 40 horas, pagadas como si fueran 48.

Ha sido éste un duro golpe para las centrales sindicales, especialmente para la poderosa Confederación General del Trabajo, de estricta obediencia comunista que, por primera vez, ve cundir en las bases una indisciplina, producto del contagio con los extremistas estudiantiles. Es, en efecto, digno de anotarse que la rebelión se ha producido entre los obreros más jóvenes.

Es muy probable que, como la rebelión ha sido notoria en las empresas nacionalizadas, el Gobierno se vea obligado a ceder nuevamente, seguido por el sector privado ya que, sobre las bases acorcladas en la reunión tripartita, van a iniciarse ahora negociaciones al nivel de las propias fábricas.

La situación de parálisis total es muy grave. No sólo están cerradas las usinas, grandes y pequeñas, sino que muchas de ellas están ocupadas. El gas y la electricidad siguen manejados por los obreros que, cuando es necesario presionar, cortan la corriente y 
disminuyen la presión, como simple advertencia. El paro afecta absolutamente a toda la locomoción colectiva. No han faltado los alimentos básicos, pero sí suben los precios. Es ya imposible encontrar azúcar, aceite $y$, en algunas regiones de Francia, harina. No hay bencina para los particulares y los diplomáticos estamos severamente racionados. Las dificultades insalvables en materia de locomoción han provocado el cierre paulatino de las oficinas y del comercio pequeño (el grande está en huelga desde hace varios días). El Gobierno sabe que la situación actual no puede prolongarse mucho más y que puede ceder el paso a la desesperación.

El rechazo por las bases de las negociaciones tripartitas ha significado un elemento nuevo en la política francesa. Demuestra que el sometimiento a las centrales sindicales no es ya absoluto por parte de los obreros y que la insurrección de la juventud estudiantil ha afectado también a la juventud obrera.

Ello es especialmente peligroso para el Particlo Comunista que ha tenido una actitud zigzagueante frente al movimiento de los estudiantes. El 3 de mayo, en "L'Humanite", Georges Marchais denunciaba el sabotaje, la influencia pro-china y condenaba a los "falsos revolucionarios a los que había que clesenmascarar". Aun a riesgo de ser tilclado de chauvinista, atacaba al "anarquista alemán CohnBendit" (cuya expulsión de Francia, se dice, habría sido pedida por el propio Particlo Comunista) y criticaba al "filósofo alemán Herbert Marcuse que vive en los Estados Uniclos"... Las condenaciones a los "pretendidos izquierdistas" y a los "aventuristas" continuaron hasta que el movimiento estudiantil, especialmente debido a la brutalidad de la represión policial, se desarrolló en forma impresionante. Entonces trató de "recuperarlo" pero siempre con advertencias respecto al "aventurismo" de algunos de sus líderes. El tercer viraje se produjo cuanclo el Partido Comunista vio que la "recuperación" no tenía éxito y' que los grupos extremistas seguian dominando a los estudiantes. Sus ataques se reiniciaron contra el movimiento "22 de Marzo", dirigido por un Cohn-Bendit "desconocido" para el Secretario General de la CGT, Seguy... Prosiguieron en seguida contra la propia U.N.E.F. (Federación de Estudiantes) hasta llegar al extremo de que en la manifestación de ayer, el Partido y la G.G.T. prohibieron la participación de sus miembros. La ruptura parece ahora delinitiva, a menos que se produzca una nueva "volte face"... (media vuelta - cambio súbito de opinión).

Todo ello no es de extrañar. Desde hace años el Partido Comunista francés ha condenado el "aventurismo" político y no puede ver con buenos ojos que la juventud critique, por igual, a Françnis Mitterand y a Charles de Gaulle, cuando el primero es un aliaclo 
electoral y parlamentario muy importante y cuando se está jugando lealmente el juego democrático. EI Partido Comunista no es, en efecto, en este momento un partido propiamente revolucionario y muchos de sus electores se acomodan bien de la tan repudiada "sociedad de consumo". Sus aspiraciones actuales residen en llegar al Poder conjuntamente con otras fuerzas "democráticas".

Por eso no puede aceptar a un anarquista como Henri CohnBendit ni a un "hereje" como Herbert Marcuse.

Además, es un hecho que toda la revolución que se ha producido en Francia -empleo el término "revolución" porque tengo el convencimiento de que nada será en el futuro igual a la Francia anterior al mes de mayo de 1968- está siendo aprovechada, no sólo por los enemigos jurados del Partido Comunista, trotzkistas, maoístas, o anarquistas, sino que también por el PSU, animado por Pierre Mendes-France y, en el plano sindical, por otra Confederación realmente importante, la CFDT (separada de la CFCT) que, a rio revuelto, están buscando y obteniendo adeptos.

Por último, para explicar la posición de los comunistas, hay que tener presente que ellos saben que, solos, nunca vencerán al "poder gaullista" y que si se produce una reacción ante el desorden extremo, los comunistas serán quienes pagarán, como siempre, las consecuencias.

En cuanto a los estudiantes, después de las violentísimas manifestaciones del viernes pasado, que dejaron más de 500 heridos, han recapacitado también y las últimas instrucciones son de evitar la provocación. Debido a ello, la manifestación estudiantes-CFDT se desarrolló ayer en calma. Este cambio se debe seguramente a dos factores. Primero, el temor a un encuentro violento con las fuerzas de orden que habian recibido instrucciones de disolver de inmediato cualquier tentativa de construir barricadas, en vista que se sabía -lo que es efectivo- que los estudiantes tienen armas escondidas. Segunda razón: evitar el temor, que ya existe entre los franceses en grado sumo, a fin de que éste no se constituya en un factor determinante en el próximo referéndum. Las influencias moderadoras del PSU y de la CFTD se han dejado también sentir en estas directivas.

La única personalidad política que goza de prestigio entre los estudiantes es Pierre Mendes-France, lo cual molesta sobre manera a François Mitterand y a sus amigos de la Federación Tengo la impresión que durante la semana pasada, si Pierre Mendes-France hubiera querido aprovechar, con fines propios, el movimiento estudiantil y las huelgas, hubiera podido tomarse el Gobierno. No lo hizo, entre otras razones, porque es terriblemente indeciso y porque es un "solitario". 
¿Cómo el país más rico de Europa, con un Gobierno estable, con una constitución política ágil, ha podido, en tres semanas, estar al borde de la hecatombe, de la revolución social y en una crisis. sin precedentes?

Nadie ignora que existía un cansancio en el orden político frentea un Gobierno fuerte que lleva diez años y, sobre todo, frente al hecho de que un mismo equipo sigue gobernando al país; que existía un descontento porque siempre figuraban los mismos Ministros. y las mismas personalidades. Ello lo comprueba el hecho de que el General hubiera tenido que luchar denodadamente para lograr, al final del año 1965, sólo un $55 \%$ de los votos en la elección pre-
sidencial.

Nadie ignoraba tampoco que existía descontento en las masas. obreras y campesinas, que sus reivindicaciones no eran consideradas. ni sus problemas solucionados prontamente; que la injusticia social era violenta, entre una clase adinerada e insolentemente lujosa y un proletariado, si no miserable, por lo menos enfrentado a una difícil' situación económica.

Nadie ignoraba tampoco que la Universidad estaba con esclerosis. y necesitaba modificar sus estructuras que datan de la época de $\mathrm{Na}-$ poleón el Grande.

Nadie ignoraba tampoco que el país sentía falta de consideración por parte del régimen. Valéry Giscard d'Estaing, en reciente discurso, recordaba, con razón al "Pigmalión" de George Bernard Shaw. El profesor reprocha a la vendedora de flores su mirada hostil después que la ha instruido, la ha transformado en una dama de la sociedad y se la oye contestar más o menos lo siguiente: "He. recibido todo de Ud., salvo la consideración..."

Pero nadie pensaba que en tres semanas Francia podría llegar. a la situación en que hoy se encuentra. La verdad es que todos han. sido sorprendidos por la violencia de los estudiantes, explicada, sólo. en parte, por la brutalidad de las primeras represiones policiales, $r$ seguida por la violencia de las reivindicaciones obreras y camnesinas..

Cuando los primeros se lanzaron contra el orden público, social. y económico establecido, los segundos siguieron y ensancharon el camino.

Es cierto que las reivindicaciones de los estudiantes comenzaron. por tener objetivos limitados; la reorganización de los estudios, del sistema de exámenes, la cogestión y el problema de la ocupación post-estudiantil. Es cierto asimismo que los obreros comenzaron porpedir mejores condiciones económicas y de trabajo, y también la cogestión.

Pero el estilo fue diferente. Mientras los estudiantes atacan el 
sistema capitalista, a la burocracia, a la tecnocracia y a una sociedad injusta y reclaman el derecho de participar en la construcción de la del futuro, los obreros buscan acomodarse mejor en una sociedad que, sin embargo, califican de explotadora.

Por eso creo cada vez más que Herbert Marcuse tiene razón cuando clice que las víctimas de la sociedad tecnológica actual no son los asalariados (por lo menos en un país desarrollado) sino que la juventud $y$, especialmente, la juventud intelectual. Esto explicaría la diferencia cle objetivos y de métodos, la violencia de unos, la resolución tranquila de los otros.

Es un grave error, los trágicos sucesos de Francia lo demuestran, contrarrestar los cleseos de transformación de la sociedad que animan a la juventud y sostener que se trata de ilusiones que nada tienen que ver con la realidad.

¿Qué va a suceder en Francia?

Al recibir las credenciales del nuevo Embajador de los Estados Unidos, en plena crisis, Charles de Gaulle le dijo en su discurso de respuesta: "El porvenir, señor Embajador, no depende de nosotros. Depende de Dios".

Por vez primera, Charles de Gaulle ha cedido la precedencia a Dios...

\section{9 de majo}

Ayer se pudo comprobar que, a pesar de los extraordinarios esfuerzos realizados por Georges Pompidou en estos clías y noches consecutivos, los acuerdos a los cuales llegaba con los dirigentes sinclicales eran rechazados en las fábricas por las bases obreras que, viendo al Gobierno debilitado y recibiendo influencias de elementos extremistas, peclían nuevas concesiones y encontraban insuficientes aquellas por las que habían luchado, sin resultado, clurante meses $y$ años y que les eran acordadas ahora con relativa facilidad.

En los momentos más críticos, el Partido Comunista y la Confederación General del Trabajo, controlada por aquel, anunciaron para hoy una concentración llamada a constituir una gran demostración de fuerzas. Invitaron a las demás centrales sindicales; pero Ja F.O. controlada, a su vez, por el Partido Socialista, declaró que no asistiría, por cuanto no tendría un carácter sindical, sino que político. Por otra parte, la principal rival de la CGT, la Confederación Francesa de Trabajadores Democráticos (CFTD), puso como conclición que se invitara también a las organizaciones estudiantiles. La CFDT, ha tenido, en efecto, como táctica, atraer al movimiento .estudiantil, derribando, en cada oportunidad que se le ha presentado 
los muros que pretende levantar el Partido comunista entre estudiantes y obreros. Pero, como el Particlo Comunista insistiera en su negativa para invitar a los elementos juveniles, fuertemente influidos por trotzkistas, maoístas y anarquistas, la CFDT no se hizo representar.

La concentración recorrió en perfecto orden, la distancia existente entre la plaza de la Bastilla y la estación San Lázaro. Se ha calculado en quinientos mil el número cle asistentes; pero en lugar de ser gremial tuvo un carácter netamente político. Las reivindicaciones sindicales cedieron el paso a los anhelos políticos de izquierda, resumidos en un slogan "Queremos un Gobierno Popular", unidos a virulentos ataques al Presidente de la República y al Gobierno.

\section{VACíO DE PODER}

En estos momentos cinco fenómenos son visibles: una revolución instalada en las Universidades y otra en las fábricas; un Poder Ejecutivo ausente y sin mando real, a pesar de los esfuerzos notables de Georges Pompidou; los partidos políticos de Oposición, con la excepción de los comunistas, sin arrastre popular alguno y el Partido Comunista tratando de agarrarse de los faldones de los obreros que han caído en el "aventurismo"; las fuerzas armadas, poco seguras y sin deseos de intervenir a estas alturas para restablecer el orden; una inmensa masa de opinión, sin duda mayoritaria, desorientada $y$ asustada. Tal como van las cosas, me parece ocioso preguntarse cuál será el resultado del referéndum anunciado para el 16 de junio. Mejor es preguntarse si habrá tal referéndum.

En la tarcle, se conoció el "coup cle théâtre" (golpe de teatro) de la partida de Charles de Gaulle a su propiedad de campo. Dejando en la mayor ignorancia a sus más cercanos colaboradores partió, en compañía de su esposa y en helicóptero, a Colombey-les-deux Eglises. Había convocado, sin embargo, a un Consejo de Gabinete y, a medida que los Ministros llegaban, los ujieres les anunciaban que el Presidente había particlo y que la reunión queclaba postergada para mañana. El más difícil de convencer era el Ministro André Malraux quien, ensimismado en sus propios y elevados pensamientos, insistió en penetrar en la sala del Consejo, sin comprender que quien lo había citado había literalmente emprendiclo el vuelo.

$\mathrm{El}$ anuncio del viaje sorpresivo del General ha produciclo el mayor desconcierto en todos los círculos. Se han hecho, como es natural, toda clase de suposiciones y de especulaciones. Se estima como lo más lógico, que al igual que en otra partida famosa, en 1946, a Colombey, se quedaría allá -ahora hasta el fin de sus días- "seul 
avec son chagrin" (solo con su pena), abandonando a los desagradecidos franceses a su propia suerte, es decir a la anarquía.

De buena fuente sé que Charles de Gaulle, al regresar mañana: leerá un mensaje al país que podría contener o su renuncia, o una convocatoria a elecciones generales con disolución de la actual Asamblea y cambio del Ministerio; o bien que asumiría los plenos poderes a que, en caso de peligro para la Nación, está autorizado por la Constitución.

En la noche, mi colega italiano me confirma la noticia que hetenido por otro conducto, de que hay concentración de paracaidistas en los alrededores de París.

Como en casa de Jean Nanterre, gaullista convencido, quien me informa que, con otros jefes de la que fuera la Segunda División Blindada, que liberó a París, están decididos a hacer mañana una demostración en los Campos Eliseos, no en favor del General, sino de "Trancia". No cree en la "huida" de Charles de Gaulle; pero está perplejo. Durante toda la cena, recibe llamados telefónicos y los hace él para organizar el desfile de mañana. "Los que salvamos a Francia en 1944 -me dice- aunque fuimos pocos, daremos un ejemplo y un testimonio".

Por suerte, Georges Pompidou continúa heroicamente en su "maratón" de conversaciones con los sindicatos, haciendo recordar a un poderoso motor que sigue marchando, pero en banda, sin que sus fuerzas sirvan para nada porque se ha desprendido la correa que lo une con el eje y los engranajes.

Durante todas esas horas de la tarde de ayer y la noche, que se hicieron más largas por la incertidumbre, Francia presentó el aspecto físico y moral de un "vacío de poder". Mientras los comunistas desfilaban, no se veían fuerzas del orden; los automovilistas estacionaban los poquísimos autos que aún podían circular por la falta absoluta de bencina en donde se les ocurría; la gente se juntaba en las aceras y calles a discutir sobre el futuro alarmante. Hasta Henry Cohn-Bendit, a quien las autoridades habían prohibido la entrada al país, apareció en la Sorbonne y convocó, sin ser molestado, a una conferencia de prensa.

- En la ciudad Universitaria, los estudiantes extranjeros, que no han sido los menos extremistas, se tomaron las Gasas del Brasil, de España, de Portugal, de Grecia y de Argentina. Esta última fue bautizada "Casa Che Guevara". Como el escudo argentino había sido pisoteado por los manifestantes, el Embajador Aguirre Legarreta 'estimó oportuno protestar ante el Quai d'Orsay y oyó al Secretario General contestarle que, en esos momentos, la autoridad nada podía hacer. 
Al mismo tiempo que el poder legal aparenta ya no existir, se presenta el fenómeno curioso de que la oposición política organizada no es capaz de apoderarse de ell, por cuanto no cuenta tampoco con la confianza de los movimientos estudiantiles y sindicales.

En las últimas horas de la noche de ayer el Presidente de la Federación de Izquierda, François Mitterand, hizo una declaración por radio y televisión en que denunció la carencia de Gobierno, lo instó a abandonar oficialmente el poder y propuso la designación de un Gobierno, presidido por Pierre Mendes-France, el cual debía llamar a elecciones. François Mitterand anunció que él sería el candidato de la Izquierda francesa a la Presidencia.

Hoy, después de una entrevista entre Pierre Mendes-France y François Mitterand, el primero se dirigió al país por radio. En forma calmada y objetiva, como si fuera el verdadero Jefe de un Gobierno "de facto", habló a la nación. Señaló que aceptaba el ofrecimiento de presidir un Gobierno Provisional, formado exclusivamente por los partidos de izquierda, incluyendo el comunista. Dicho Gobierno realizaría de inmediato la reforma de las estructuras sociales y económicas que habian conducido a la crisis actual. Nada dijo de nuevas elecciones y dio la impresión de que éstas serían postergadas para dejar en libertad al Gobierno Provisional. Anunció, en realidad, un verdadero estado revolucionario.

La primera reacción del Partido Comunista ha sido contraria. Aceptó la creación de un Gobierno Provisional; pero hizo reservas respecto a la persona de Pierre Mendes-France como su presidente. Indicó, como pretexto, que la Izquierda no debía aceptar el retorno al "culto de la personalidad" ni creer en el "hombre-milagroso". Es obvio que ve en Pierre Mendes-France el peligro de un líder democrático, con arrastre en la juventud y en el pueblo, capaz de arrancar de manos del Partido Comunista la dirección del movimiento revolucionario.

\section{0 de mayo}

Mientras la radio oficial, ocupada por los huelguistas, repetía a cortos intervalos las declaraciones de Pierre Mendes-France y las reservas del Partido Comunista, se han producido dos hechos que han enervado aún más a la opinión pública. Por una parte, se supo que en su viaje de París a Colombey-les-deux Eglises Charles de Gaulle había empleado ocho horas en helicóptero, cuando sólo necesita, como máximo, dos. ¿Dónde había estado el General, ya que no había pasado seis horas volando? Por otra parte, se anunció que hablaría 
por radio en la tarcle, ya que la televisión estaba en huelga, lo que es sólo parcialmente verídico.

\section{EL GENERAL CALZA LAS BOTAS}

El General, que ha elegido la soledad para adoptar sus decisiones, la escogió también para transmitirlas al país. Hizo salir de su escritorio a los Ministros, fotógrafos y técnicos de radio. Nada le importaron los problemas de transmisión. Necesitaba la concentración de su pensamiento.

Fue una declaración muy seca y por la radio se podían escuchar los golpes de puño sobre el escritorio con los cuales acompañaba sus frases cortantes que encerraban, cada una, una determinación fundamental.

Los franceses comentaron de inmediato que, a diferencia de su último Mensaje de siete minutos, ahora "volvía la vieja voz", que "el General había calzado las botas de 1940 y 1958". Con ello logró galvanizar a sus partidarios, los reunió en torno suyo y devolvió la calma a un inmenso sector de la población que estaba desamparado.

Inmediatamente después, se realizó la última sesión de la actual Asamblea Nacional; no ya para oír al Primer Ministro, como estaba anunciado, sino para escuchar la lectura de una carta de cuatro líneas, en que el Presidente de la República comunicaba que, de acuerdo con la Constitución, procedía a la disolución de la Asamblea.

La misma tarde, y durante la noche, se realizó la manifestación de los partidarios del General Charles de Gaulle. El llamado inicial para su realización había sido hecho en plena crisis por los antiguos oficiales y soldados de la famosa "División Leclerc", que liberó a París en 1944. Su objetivo era clefender "las instituciones republicanas". Pero, después del discurso del General se transformó en una inmensa manifestación gaullista. Una masa humana completó el espacio comprendiclo entre la plaza de la Concordia y el Arco de Triunfo. Según unos, había medio millón de personas, según otros, un millón.

En todo caso, la manifestación se caracterizó por su espontaneidad y por el entusiasmo de los asistentes. Había mucha juventud, pero poco elemento obrero. Constituyó un éxito extraordinario, sobre todo si se toma en cuenta el escaso tiempo con que fue preparada, la falta absoluta de movilización colectiva y particular y el sitio en que se desarrolló, tan alejaclo de los barrios populares.

Las importantes fuerzas de orden, insultadas en todas las concentraciones de los estudiantes, vieron esta vez, con estupor y agrado, que los manifestantes las aplaudían, lo cual, además de constituir 
una alentadora novedad les ha devuelto la moral, que se encontraba: bastante baja después de 15 días de violentas luchas callejeras.

Este retorno a la esperanza de mantener el orden amenazado, no significa, en forma alguna, que la situación haya tenido un viraje efectivo hacia la solución de los problemas laborales. Hay en este momento todavía entre nueve y diez millones de trabajadores en huelga y muchísimas fábricas siguen ocupadas. El país está totalmente detenido, pero hay esperanzas de que el nuevo Ministerio en formación pueda continuar las conversaciones con los gremios con un éxito mayor que el que hasta el momento se ha alcanzado.

Los días críticos, no en lo político sino que en lo laboral, van a continuar y la economía nacional seguirá desmoronánclose.

Pero es evidente que la esperanza ha resurgido en quienes no están ni con los estudiantes en la Sorbonne, ni con los huelguistas en las. fábricas. Ellos forman la gran masa de los ciudadanos aislados, temerosos de ver instalada en Francia la anarquía o el comunismo. Es la Legión de quienes forman el "Partido del Miedo". Ellos, con o sin reserva, han captado el llamado del anciano héroe de la guerra. Por segunda vez, después de 28 años, han escuchado la voz que los. llama en nombre de la patria en peligro y han respondido.

Esta masa se agrupa ahora, como en la crisis de 1958, junto a Gharles de Gaulle. Ello es importante en un país en que los partidos políticos, con la sola excepción del Comunista, no tienen vida permanente y sólo actúan en vísperas de las elecciones $y$, sobre todo, en que la Juventud es apolítica.

La crisis actual no ha terminado pero las posiciones están definidas. Sólo se alejará cuando se hayan producido las reformas de estructura que este país tanto necesita. Hoy, debido a la terrible crisis que se ha desencadenado en forma tan imprevista, todos se declaran dispuestos a sacrificar una parte de su bienestar en aras de la justicia social. Pero abrigo el temor de que la crisis haya sido demasiado corta y, por lo tanto, el miedo sea pasajero. No vaya a repetirse lo acontecido después de la Revolución Francesa, cuando los emigrados regresaron a su patria "sans avoir rien appris, après avoir tout vu" (sin haber nada aprendido después de haberlo visto todo).

Ojalá mis temores sean infundaclos.

\section{1 de mayo}

Ahora he tenido la explicación de las seis horas de "paradero desconocido" del General. Voló a Mulhouse a entrevistarse con su yerno que comanda la más potente división blindada del Ejército del Rhin, y después a Baden-Baden, en Alemania, donde logró el apoyo del 
ejército de ocupación estacionado y comandado por el General Massu. Es decir, que mientras los políticos se repartían sus despojos, el Presidente conquistó el apoyo de las tropas de élite y de las divisiones blindadas, algunas de las cuales se dirigen ahora a los alrededores de París.

Digno es de señalar que el General no ha estimado conveniente dar ninguna explicación respecto a estas entrevistas, ni tampoco sobre su aterrizaje en territorio alemán. Tampoco lo hará. Es su sistema: hablar poco y obrar rápido. Como aquí no existe el precepto constitucional, heredado de las Leyes de Indias, de que el Presidente de la República necesita permiso del Parlamento para salir del territorio nacional, nadie podrá hacerle una acusación constitucional...

El discurso de ayer del General debe ser analizado, dado su considerable importancia.

Comenzó por expresar que en las últimas 24 horas ha analizado, sin excepción, todas las eventualidades que le permitían mantener la "legitimidad nacional y republicana". Tales eventualidades consistían en: cambiar al Primer Ministro, decretar el "estado de alerta", el "estado de urgencia", el "estado de sitio", aplicar el artículo 16 de la Constitución, renunciar a su cargo, disolver la Asamblea Nacional.

Veamos en que consisten estas alternativas.

Un decreto ley de 7 de enero de 1959 permite al Presidente de la República, con el acuerdo del Consejo de Ministros, o a las autoridades locales, en caso de interrupción de las comunicaciones internas, clecretar el "estado de alerta". El Poder Ejecutivo y sus agentes están autorizados a aplicar las medidas necesarias para combatir una agresión interna o externa. Pueden requisar las personas y los bienes y racionar los alimentos y otros artículos de primera necesidad.

EI "estado de urgencia", según una ley de 1955, puede ser declarado por el Gobierno "en caso de peligro inminente resultante de graves atentados al orden público", y sólo por un máximo de 12 días. Una prolongación requiere autorización de la Asamblea Nacional. Permite reglamentar y prohibir la circulación de los ciudadanos, establecer zonas especiales de protección, autorizar a los intendentes a detener en sitios especiales a determinadas personas, a clausurar sitios públicos y allanar los domicilios de día y de noche. Se puede, asimismo, aplicar la censura a la prensa y a la radio. Un simple decreto puede dar autoriclad a los tribunales militares para conocer asuntos que son de la incumbencia de los tribunales ordinarios.

$\mathrm{El}$ "estado de sitio", está previsto en el artículo 36 de la Constitución. El Ejecutivo lo decide hasta por 12 días (para un plazo mayor se necesita la autorización de la Asamblea Nacional) en casos de 
peligro inminente resultante de una guerra extranjera o de insurrección armada. En tal evento, todos los poderes pasan a depender de la autoridad militar.

El Artículo 16 de la Constitución prevé que cuando el funcionamiento regular de los poderes públicos constitucionales se ha interrumpido, el Presidente de la República adopta por decretos leyes las medidas que las circunstancias exijan. El Parlamento se reúne entonces de pleno derecho.

El General tenía, pues, a su disposición un buen acopio de textos legales de los cuales podía echar mano. Decidido a no renunciar y a no cambiar el Primer Ministro, que es de su confianza mientras no sea derribado por la Asamblea Nacional, y a quien le prodigó frases de halago inusitadas en el Presidente ("su valor, su capacidad y solidez merecen el homenaje de todos"), clecidió no utilizar dichos textos, que le habrían valido la acusación de "clictadura" y, en cambio, disolvió la Asamblea.

Políticamente, fue un gesto muy hábil ya que obligó a la Oposición y al Partido Comunista a pronunciarse. Si se negaban a concurrir a las elecciones, no sólo ingresaban a la ilegalidad, sino que reconocían públicamente que no eran mayoría en el país. En cambio, si aceptaban las elecciones, tenían que cooperar al término de las huelgas, ya que el período pre-electoral es muy corto. Efectivamente, las elecciones han sido fijadas para el 23 de junio, quedando sólo tres semanas para la preparación de las mismas y 10 días para la inscripción de candidaturas. Es evidente que el estado de huelga perjudica sobre todo a la Oposición.

Buscando la solución democrática de la consulta al pueblo, el General desvirtúa nuevamente su capacidad táctica. En seguida, manifiesta que el referéndum anunciado en su anterior mensaje al pais, queda postergado. No habría tenido éxito y la consulta estaba mal formulada y era de difícil comprensión. Dato, además, curioso: estando en huelga la imprenta del Estado, no había podido iniciarse la impresión de las cédulas. Se pretendió imprimirlas en Bélgica, pero los tipógrafos de ese país se negaron por solidaridad con los obreros franceses.

Respecto a las elecciones para la Asamblea Nacional (no se disuelve el Senado "conservador"), ellas se clesarrollaxán libremente, "a menos que se pretenda amordazar al pueblo francés impidiéndole expresarse, así como se le impide vivir, y por los mismos medios que se impide a los estudiantes estudiar, a los profesores enseñar y a los trabajadores trabajar": "Estos medios son la intimidación, la intoxicación y la. tiranía, ejercitados por grupos organizados desde hace tiempo y por un partido que es una empresa totalitaria, aun cuando tenga ya riva- 
les en esta materia". No se podía ser más claro y más hiriente para el Partido Comunista.

Si tal situación se mantuviera, el General usará los otros medios que la Constitución le brinda.

Pero, en todo caso, en todas partes y de inmediato, debe organizarse la "acción cívica". No se trata de una organización administrativa, sino que de un llamado a la cooperación de los ciudadanos con el Gobierno, a la creación de comités que cooperen con las autoridades o manifiesten su apoyo a las instituciones. La manifestación del día 29 es un ejemplo de esta acción. En las provincias también ya se han creado "comités de acción cívica", formados por ciudadanos de tendencias políticas diversas, pero que desean cooperar con las autoridades.

Los Intendentes pasan a ser "Comisarios de la República". La terminología recuerda los "Comisarios Políticos" de la Revolución Francesa y a los "Comisarios de la República" de la Liberación, creados por el propio Charles de Gaulle. En tal condición, pueden tomar medidas para reorganizar la vida económica $y$, eventualmente, decretar el "estado de alerta".

Todas estas medidas, el Gobierno las toma porque "Francia está amenazada de dictadura". "Se quiere obligarla a que se resigne a aceptar un poder que se impondría en la desesperanza nacional, un poder que sería esencialmente el poder del vencedor, es decir del comunismo totalitario". Aunque cuando el Partido Comunista ha variado y ha jugado en la crisis el juego democrático, cometió el error, la víspera del discurso del General, de pedir "el cambio de régimen" y el "establecimiento de un Gobierno popular". De allí se basó Charles de Gaulle para agitar el espectro del comunismo, que sigue espantando a la mayoría del pueblo francés.

$\mathrm{Y}$ para atacar al propio tiempo a François Mitterand y a Pierre Mendes-France y a quienes habían osado pretender al mando, creyendo que estaba vacante, el General agregó: "Naturalmente se le pintaría (al Comunismo) con colores mentirosos, utilizando la ambición y el odio de políticos desplazados". "Después de lo cual, esos personajes no pesarían en el Gobierno más de lo que pesan ellos mismos, lo que no es mucho".

Termina manifestando: "No. La República no abdicará. El pueblo reaccionará. El progreso, la independencia y la paz se impondrán, junto con la libertad".

El General volvió a ser el mismo de 1940 y de 1958. Supo, en el último extremo, calzar las botas y logró con su discurso gálvanizar a sus partidarios decaídos y a la gran masa de los franceses que "estaban desorientados, desamparados. Borró con este mensaje, el efecto 
desastroso de su anterior discurso, tan esperado y tan decepcionador, en que, como solución para los problemas de Francia, anunció el "referéndum" que ahora queda postergado hasta las calendas griegas.

Demostró a los políticos que Charles de Gaulle estaba decidido al combate y que el cargo de Jefe de Estado no estaba vacante; a los huelguistas, que fuera de los sindicatos había una masa de ciudadanos. que no compartían su actitud, si bien podían comprender sus aspiraciones; y a los estudiantes que no eran dueños absolutos de la calle.

\section{2 de junio}

Confirmado en su cargo por Charles de Gaulle, Georges Pompidou ha reorganizado su Ministerio, pero sin ampliar su base de sustentación. La principal novedad consiste en el nombramiento de René Capitant, jefe de los Ilamados "gaullistas de izquierda", como Ministro de Justicia. Dos otros diputados de esta misma tendencia, Dechartre y Morandat (el que, sin más compañía que su esposa, se tomó, el Palacio del Jefe de Gobierno, a xaíz de la Liberación), entran como Secretarios de Estado. Michel Debré y Maurice Couve de: Murville intercambian sus Ministerios y va, el primero a Relaciones; Exteriores y, el segundo, a Finanzas. Dejan el Gabinete los personajes; que, con la excepción de Georges Pompidou, tuvieron una actuacióne más destacada y, por tanto, más criticada, en los incidentes últimos: Louis Joxe, que reemplazaba al Primer Ministro durante su ausencia en Afganistán y en Irán; los señores Peyreffitte, Ministro de Educación; Fouchet, del Interior; Missofle, de la Juventud y Deportes y Gorse, de Informaciones.

Este es el Ministerio que presidirá las elecciones fijadas para los domingos 23 y 30 de este mes en curso.

A pesar de que la huelga general sigue su curso hasta la fecha y las negociaciones no han progresado, debido en parte a los dos días festivos de Pentecostés, los partidos políticos han iniciado ya sus preparativos electorales, en vista de que tienen sólo hasta el día 10 como plazo para presentar candidatos.

La Federación de Izquierda ha propuesto al Partido Comunista llevar una candidatura única para el primer escrutinio y obtener así un gran número de elegidos el día 23. Pero, el Partido Comunista, ha contestado que prefiere presentar candidatos propios en todas las circunscripciones y ha pedido que, para el segundo escrutinio, se desistan los candidatos menos bien colocados. Esta respuesta ha creado un ambiente un tanto desagradable en la Federación, que teme: verseobligada a apoyar al candidato comunista y dar así la impresión de que se encuentra a la zaga del extremismo. 
El mismo problema se ha suscitado en los dos partidos de Gobierno. Los "giscardianos" han pedido al gaullismo el siguiente pacto electoral: se presentará como candidato de la actual mayoría aquel que haya estado en funciones hasta la disolución de la Asamblea, cuando el puesto pertenezca a un gaullista o a un "giscardiano". En los otros casos, se presentarán separados, para el primer escrutinio, candidaturas gaullistas y "giscardianas"; apoyándose en el segundo escrutinio, aquellas que tengan mayor número de votos. Esta petición no ha sido acogida, en principio, por los gaullistas puros que clesean tener en la próxima Asamblea un conglomerado más homogéneo y no depender de los llamados "oui... mais" (Sí... pero...).

Hay, pues, una marcada tendencia a la bi-polarización. No me atrevo a estas alturas a hacer pronósticos sobre los resultados de los próximos comicios; pero me parece evidente que la bi-polarización va a perjudicar especialmente al Centro Demócrata, situado entre ambos bandos, hoy más irreductibles que nunca y va a favorecer, dentro de las actuales formaciones, a los definidos, es decir, a los gaullistas y a los comunistas.

Es muy: difícil, en las actuales circunstancias, predecir también la influencia que tendrán en las elecciones las huelgas de obreros y estudiantes. Se ha notado en la masa obrera, después del discurso del General Charles de Gaulle, el deseo de hacer predominar las reivindicaciones económico-sociales sobre la agitación política. ¿Hasta que punto el Partido Comunista será capaz de impedir que estas reivindicaciones alcancen niveles imposibles de satisfacer? ¿Será capaz el Partido Comunista de "saber terminar una huelga" y seguir el ejemplo de Thorez, en 1936, cuando la agitación social se detuvo al subir al poder el Frente Popular, dirigido por León Blum?

En cuanto a los estudiantes, la agitación continúa, pero es evidente que están embargados por un sentimiento de soledad. Soledad lógica con respecto al gaullismo; pero soledad también con respecto a los partidos políticos de Izquierda y a las Centrales Sindicales. Este sentimiento, que puede transformarse en frustración en una juventud idealista y valiente, es capaz de llevarla a nuevas acciones extremistas para impedir la realización pacífica de las elecciones. En el Quartier Latin ya se oye el "slogan", "Des élections, pourquoi faire?" (¿Elecciones, para qué?). Tal vez pudiera resumir hoy el pensamiento de los estudiantes que ocupan la Sorbonne, el Odeón y las diferentes Facultades, en los siguientes términos: "Sabemos que, sin el apoyo obrero, estamos destinados a la masacre. Pero no estamos combatiendo para nosotros, sino para nuestra generación. Los partidos de Izquierda. y las Centrales Sindicales son capaces de acomodarse en la sociedad 
Emique Bernslein / Situación politica en vísperas de mayo do 1968

imperante. Pueden dejarnos solos. Podemos fracasar a menos que sigamos presentes en la lucha".

En todo caso, me parece que las próximas elecciones, ya sea que ellas se realicen en la forma pacífica acostumbrada o dentro de] desorden, deberán tener como objetivos la solución de los problemas económicos y sociales que afectan a Francia y que se han hecho patentes en las últimas semanas.

Sólo ahora he sabido las previsiones hechas por algunas de las más notables pitonisas, en diciembre pasado, y con miras al año en curso: Madame Orion decía entonces: "El General Charles de Gaulle conservará el poder, pero cambiará al Ministerio. Las reformas sociales se intensificarán. Grandes huelgas a comienzos de año".

Madame Vidi cleclaraba: "El General Charles de Gaulle dominará más fácilmente los peligros que vienen del exterior que las presiones internas. Mis manchas de tinta me lo muestran rodeado de gorros frigios. Una lluvia de reformas inundará a Francia".

Y Madame Bouvier, decía por su parte: "Veo tormentas políticas, huelgas y dificultades económicas en la primera (europea), habrá una mejoría en el verano. El General Charles de Gaulle se mantendrá en su puesto. Sin embargo, veo para él una pérdida de prestigio en 1968".

Valdría la pena estudiar seriamente la posibilidad de nombrar a pitonisas de renombre en el personal diplomático de las Embajadas...,

\section{6 de junio}

A pesar de los esfuerzos del Gobierno y de la necesidad de preparar las elecciones, las negociaciones tripartitas siguen estancadas en los ferrocarriles, transportes colectivos, taxis, correos y telégrafos, bancos, siderurgia, industria automotriz, astilleros, educación pública y privada, etc. Sólo han regresado al trabajo los obreros de la electricidad, gas, carbón, industria alimenticia y arsenales. El aeropuerto de Orly sigue paralizado y París sin contactos aéreos con el exterior.

Esta noche hubo violentos incidentes en el Barrio Latino. Estábamos de "mirones" con mi esposa y Jorge Cash, cuando se produjo una violentísima carga de la Policía y de los CRS. Tuvimos dificultad en huir debido a la enfermedad de Cash... Peor le fue a uno de mis hijos que tomaba fotografías de las barricadas. Al arrancar de los CRS, cayó al suelo y fue salvajemente golpeado en la cabeza y en la espalda. Felizmente, las farmacias están bien provistas y no tuvo consecuencias el apaleo, frente al cual no puedo reclamar. Por. lo clemás, mis hijos estaban advertidos, desde hace semanas, que su asistencia a las manifestaciones la hacían como simples particulares. 


\section{8 de junio}

Hoy sábado, aprovecho para hacer un resumen de la situación política, social y. universitaria de Francia. Los acontecimientos que hemos vivido, y estamos viviendo, han dejado atónitos a todos los franceses sin excepción alguna. Se siguen estudianclo las causas y se liega siempre a la conclusión que no tienen relación con los efectos. Los historiadores, siempre tranquilos observadores de los hechos, han comparado las jornadas de mayo a las que Francia vivió en 1848, durante el gobierno de Luis Felipe, respetado y querido y en una nación rica, poderosa, aburguesada y en pleno romanticismo, fue repentinamente arrasada por dos días de barricadas edificadas por estudiantes y obreros. La comparación tiene muchos fundamentos, por lo menos aparentes. También Alfonso de Lamartine, había escrito en. 1848 que la Francia se aburría y el despertar fue entonces tan trágico y tan espontáneo como ahora. El resultado, a plazo no lejano, de lạs jornadas de aquel año, fue la restauración del bonapartismo.

El golpe maestro del General Charles de Gaulle consistió en la disolución de la Asamblea Nacional y en convocación en el plazo mínimo que la Constitución permite, de nuevas elecciones. Los problemas sociales fueron asi desplazados rápidamente hacia el campo político.

La campaña electoral fue iniciada por el propio General en una entrevista de prensa que el Jefe del Estado se hizo hacer por el periodista gaullista Michel Droit y que fue reproducida en la Televisión. A mi juicio es una obra maestra, digna de figurar en la antología gaulliana. El General demostró de nuevo sus condiciones de gran actor. Estaba hasta de buen humor, tranquilo, seguro de sí mismo. No me voy a detener en analizar sus puntos de vista.

Sus declaraciones han tenido, como siempre, la virtud de entusiasmar a sus partidarios y de enfurecer a sus adversarios. Digno es de señalar, sin embargo, que los dirigentes sindicales han rechazado de plano la idea de la participación en los beneficios y en la dirección de las empresas. Ven en' esta idea, en la palabra "participación", un peligro para la propia subsistencia de las grandes centrales sindicales. Por su parte, los políticos de oposición, dándose cuenta que ella aporta algo nuevo en la campaña electoral, hacen notar también el hecho incontestable que el General, que sólo ahora recuerda que fue: "revolucionario", ha debido esperax los últimos y graves acontecimientos para imponer una idea que él sostuvo hace veinte años, cuando estaba en la oposición, en la "travesía del desierto".

En todo caso, la entrevista del General adelanta lo que será la 
campaña electoral del gaullismo. Ella estará dominada por dos principios: el anti-comunismo y la "participación".

"La participación" aunque no es novedosa, es atrayente, sobre todo para quienes, como el propio Charles de Gaulle no se sienten atraídos ni por el comunismo ni por el capitalismo y menos aún por la sociedad actual, sometida al maquinismo, con su confort, su avance científico, su prosperidad, pero también con su crueldad, sus servidumbres, su deshumanización. Pero existe una contradicción que no es prudente olvidar: la masa electoral gaullista es de derecha y la "participación" la afecta en sus principios capitalistas. Veremos entonces el caso curioso de que votan en favor de una idea quienes no la comparten. Ello es peligroso para el futuro, si es que, en realidad, se quiere establecer en la práctica la participación plena y efectiva.

Apoyándose en el anti-comunismo como idea negativa y en la "participación" como factor positivo y moderno, el gaullismo se lanza a la campaña electoral, esperando ganar los votos del "Partido del Miedo".

Para atraerse a quienes temieron que el país fuera arrasado por el extremismo o por el anarquismo, es necesario que la situación se mantenga en parte tensa y que el recuerdo de la crisis pasada no se'borre totalmente de la memoria de los electores. Para recordarles el peligro, es útil agitar el espectro del Comunismo.

En la Oposición la situación no es clara. La Federación puede combatir la participación desde su punto de vista práctico; pero el anti-comunismo la perjudica por el hecho de tener un pacto no sólo electoral con el Partido Comunista, sino también un pacto de gobierno con participación comunista. Tratan los dirigentes de la Federación, por todos los medios, de explicar que el "anticomunismo" del General es una mera treta electoral, de devolver la tranquilidad al electoraclo independiente y de asegurar que un triunfo completo del gaullismo hará caer al país en la guerra civil.

Más aún, se nota un deseo de acercamiento con el Centro. Gaston Defferre, presidente del grupo parlamentario de la Federación, en un discurso reciente ha tratado de explicar que no existe un programa común con el Partido Comunista. Por eso, en el segundo escrutinio, la Federación no está obligada a apoyar al candidato comunista si está mejor colocado, sino que, a "los republicanos progresistas" que hayan demostrado una posición anti-gaullista, es decir, a la gran mayoría de los diputados del Centro Demócrata. Hay que evitar, lo dijo claramente, un enfrentamiento entre gaullistas y comunistas: "Hay un tercer camino, el camino del progreso que permite acceder a las reformas sociales sin que corra sangre. Es él camino de la democracia socialista". 
Por su parte el Partido Comunista, que ve que la campaña electoral se hará en su contra, estrecha filas y se defiende contra sus enemigos, no sólo contra el gaullismo, sino que también contra la tendencia sostenida por Gaston Defferre y contra los "izquierdizantes" del ala extrema.

Contestando en términos violentos a Gaston Defferre, "L'Humanité" sostiene que la elección debe hacerse entre "la dictadura" y la construcción de una democracia real, social". "El tercer camino sólo conseguirá debilitar a las fuerzas democráticas". Para el Partido Comunista, sólo la unidad de la Izquierda conducirá a la derrota del gaullismo.

Si el Partido Comunista combate en su flanco derecho para evitar que la Federación se acerque al Centro Demócrata, al cual califica de "ultra-reaccionario", también debe combatir en su flanco izquierdo.

A diario, el periódico oficial del Partido ataca, con inusitada violencia, a los "grupos izquierdizantes"; acusa a quienes se oponen a que la huelga termine allí donde lo desean los obreros; denuncia a los que "calumnian" al Partido Comunista y se dedican a "actos aventuristas" con una fraseología "seudorrevolucionaria". Para "L'Humanité", tales grupos hacen el juego del poder gaullista y del patronato y combaten, por el contrario, a "las organizaciones y a los militantes que dirigen la lucha de los obreros". "Hay que denunciar en todas partes y con valor esta empresa de diversión -se lee en el órgano oficial del Partido- que podría acarrear pesadas consecuencias para el porvenir democrático y socialista de Francia, al favorecer las intenciones autoritarias y dictatoriales del poder gaullista". Aunque el diario no nombra a los autores de tal "empresa de diversión", es claro que alude a los movimientos revolucionarios estudiantiles recién creados, a los maoístas, a los trotzkistas, a los anarquistas, a todos aquellos que sostienen que hay que aprovechar los recientes acontecimientos no sólo para derribar al régimen político, sino también, y sobre todo, para cambiar radicalmente a la sociedad. Son, en efecto, estos grupos "izquierdizantes", los que acusan abiertamente al Partido Comunista de colaboración oculta con el gaullismo, de desmovilización de las masas, de reformismo, de abandono de los objetivos revolucionarios.

Es indudable que el Partido Comunista juega en Francia el juego democrático. Quiere ir a las elecciones, quiere llegar al Poder conquistando el Gobierno en los comicios y no mediante la revolución inmediata y violenta. En este aspecto electoral, concuerda no sólo con la Federación, sino que con el gaullismo. Por eso, no sólo en el terreno social, sino que también en el plano político, el Partido 
Comunista, como fuerza organizada, está distanciado de los elementos ultra-revolucionarios que han aflorado en Francia y que cuentan con la simpatía de la juventud activista.

En cuanto al Centro-Demócrata, está colocado entre dos fuegos, to que puede hacer peligrar su propia existencia, y se han hecho. visibles, una vez más, las diferentes tendencias que lo forman. Mientras su Presidente, Jacques Duhamel, declara públicamente que "no. facilitará la elección de gentes que sean los rehenes del Partido. Comunista (es decir que entre un gaullista y un candidato de la Federación, preferirá al primero), el Secretario del Partido, Pierre: Abelin, sostiene que hay más identidad entre la Federación y el Centro Demócrata que entre éste y el gaullismo. El senador Jean Lecanuet parece compartir los puntos de vista de Abelin y cree que: la salvación de Francia está en una Izquierda democrática, antigaullista, pero también anti-comunista.

El "leit motiv" de los centristas es señalar el peligro de un Parlamento dividido en dos fuerzas irreductiblemente opuestas.

En la práctica, creo que los centristas que sean elegidos, lo serán, como un mal menor, con el apoyo, según sea el caso, de las fuerzas. gaullistas o de las fuerzas de la Federación.

Por otra parte, hay que tener presente que muchos de sus miembros desean ingresar al Gobierno con Charles de Gaulle y' que éste, en su entrevista con Roger Droit, admitió la posibilidad de ampliar su actual mayoría, aunque visiblemente la solución no sea de su. agrado.

Veamos ahora cuál es la posición de los extremistas de Derecha y de Izquierda.

Los acontecimientos últimos han hecho saltar las estructuras de la extrema derecha. Tixier-Vignancour, el más violento de los opositores al General, petainista y OAS , estimó que, estando la República en peligro había que cerrar filas contra el comunismo y, tanto él como algunos de sus partidarios, han desfilado en las últimas. manifestaciones gaullistas. Ello le ha valido la expulsión del movimiento extremista que encabeza y que obedece al nombre de "Alianza Republicana" La mayoría de la directiva, encabezada por un señor Le Bourre, le acusa de colaboración y lo que es más grave, de haber negociado su apoyo al gaullismo contra las amnistías de Bidault, de Salan y de Soustelle. El hecho de que el primero haya entrado hoy a Francia sin ser arrestado, parece confirmar este acuerdo. secreto, si no con el General, por lo menos con algunas autdridades. del régimen.

Las fuerzas electorales de la Alianza Republicana son escasas, pe-

${ }^{8}$ Organización secreta del Ejército, creada durante la guerra de Argelia. 
ro sus votos pueden, dentro del sistema electoral francés, ser sufi-cientes para conseguir la derrota del candidato de la Oposición.

En cuanto a los grupos de extrema izquierda, en sus variados matices, siguen resueltos a no dejar escapar la posibilidad, que tuvieron al alcance de su mano en mayo, de derribar la actual sociedad. capitalista. No creen en las elecciones; pero sí en la acción revolucionaria. Son activos, diligentes, valientes y, creo yo, capaces de crear incidentes importantes no para impedir los comicios, pero sí, para empañar su legitimidad.

En cuanto a la situación social, gracias a la capitulación del Gobierno y al temor de los empresarios de que una prolongación de las huelgas pudiera poner en peligro el orden constitucional y gracias también a la intervención de la CGT y del Partido Comunista, se ha podido llegar a la solución de la mayoría de los conflictos sociales que tuvieron paralizada a Francia durante tres semanas. Sin embargo, por presión de los grupos extremistas, de la juventud - obrera y también de la CFDT que ha aprovechado la ocasión para "aserruchar el piso" de la central sindical comunista, muchos problemas siguen pendientes. La huelga continúa en la siderurgia, en las fábricas cle automóviles "Renault" y "Citroen", en los taxis, en parte del personal de Air France, en algunas industrias particulares importantes y en la mayoría de las grandes tiendas.

El peligro reside en que, si estos conflictos no tienen pronta solución, pueden producirse nuevas huelgas de solidaridad y ello en pleno período electoral.

Las Universidades siguen ocupadas por los estudiantes; pero se nota ya el deseo de muchos de ellos de regresar a la calma y de rendir sus exámenes. Las escuelas primarias reabrieron las clases y también lo han hecho la mayoría de las escuelas secundarias. Creo que no tardarán en hacerlo las "Grandes Ecoles" (Grandes Colegios).

El diálogo universitarios-gobierno no se ha producido porque los primeros se niegan a hacerlo y los que así piensan son los únicos organizados.

Para resolver este problema, Francia se ha encontrado con la gran desventaja de que, con excepción del Partido Comunista y de los grupos extremistas de Izquierda y de Derecha, los demás partidos políticos no tienen juventud. De allí el dominio que sobre ella ejercen maoistas, trotzkistas o anarquistas.

Los problemas de la juventud no son fáciles de solucionar porque son extraordinariamente complejos. Cuando se producen enfrentamientos violentos en Praga o en Varsovia, hay tendencia a .creer que se trata únicamente de un anhelo de libertad expresado 
contra el orden establecido; pero cuando también se producen en los países occidentales, se ve que las explicaciones simples no explican el fenómeno. En el Oeste, la Juventud rechaza la sociedad de consumo; pero en el Este, rechaza la sociedad basada en la incorporación masiva que hace predominar la escasez para incrementar la industrialización.

Pareciera que los jóvenes se agitaran en Europa movidos por una especie de insatisfacción, por la sensación de que están encerradós y prisioneros, en el Este por un sistema de propaganda y de coerción, en el Oeste por mecanismos económicos que les obligan a consumir lo que no necesitan. Tienen, en uno y otro lado de la cortina, la conciencia de que están injustamente enmarcados dentro de un engranaje técnico del cual no pueden escapar y que los utilizará hasta la liquidación del espiritu. En el fondo, creo yo, la Juventud busca la conciliación entre socialismo y libertad; pero, sobre todo, busca una nueva relación entre el hombre y el trabajo y entre el hombre y el hombre. Es un movimiento esencialmente humanista $y$, por eso, es para mí tan respetable.

Tal vez por ello mismo es que, sin concordar por supuesto, con las ideologías que predominan en el movimiento estudiantil francés, me apena verlo sobrepasado por los políticos y por los sindicatos; lamento que vaya perdiendo fuerza y que esté siendo víctima del "pourrissement." (pudxición) que provoca la inacción; y temo, por sobre todo, que caiga en la frustración, que es lo peor que le puede suceder porque le llevará a la desesperanza y a una acción esencialmente negativa.

\section{3. de junio}

La situación laboral tiende francamente a normalizarse. De los 9 ó 10 millones de obreros en huelga que paralizaron a Francia durante tres semanas, la inmensa mayoría ha regresado ya al trabajo. Sólo permanecen sin solución los conflictos en las grandes industrias de construcción de automóviles, en algunos astilleros, en algunas siderurgias importantes y en parte de la educación pública. Pero se nota un cierto cansancio de parte de los huelguistas que entran ya a la quinta semana de ocupación de fábricas. Así; los choferes de taxi han anunciado que regresarán mañana lunes al trabajo, con un alza de tarifas escalonadas que llegarán al $50 \%$ o más. Renault, la primera de las industrias en declarar el paro, debe votar el 17 el regreso al trabajo y es probable que Citroen la siga. En total, quedan unos quinientos mil obreros en huelga, la 
cual realmente no se justifica después de las ventajas obtenidas en. las negociaciones tripartitas de mayo último.

La ciudad ha vuelto a tomar el aspecto exterior normal y los turistas comienzan a regresar después de haber desertado de Francia en mayo y en la primera quincena de junio, meses claves. Se calcula que por este solo concepto, Francia ha perdido unos 300 millones de dólares en divisas.

Siempre en el aspecto laboral, las diferencias se han ahondado entre la CGI, comunista, partidaria de enfrentar las elecciones en calma total y satisfecha con los beneficios logrados, y la CFDT, que ha apoyado hasta el final, tanto a los obreros en huelga como. a los estudiantes.

Por otra parte, la muerte, de origen muy discutido, de un estudiante, provocó anteayer y ayer nuevos e importantes desórdenes en. el Barrio Latino. Se produjeron verdaderas batallas, durante ocho. horas, entre estudiantes y policias y CRS. Pero, la situación tiende hoy a calmarse, aunque el número de heridos sube de los 200 .

\section{5 de junio}

Es interesante anotar la reacción de la opinión pública. Después. de haber sido muy favorable a los estudiantes, se ha cansado ahora. de la violencia $y$, en muchos lugares, los dueños de casa, comerciantes o simples "mirones", han tomado más bien el partido de la. Policía, la cual procedió sin la brutaliclad de las semanas anteriores.

El propio diario de oposición, "Le Monde", que prestó durante toda la crisis su apoyo a los estudiantes y a los movimientos de Juventud, publicó un editorial de su director, Hubert Beuve-Mery, hecho excepcional (es la primera vez que veo su firma verdadera desde hace más de tres años) en que se pronuncia en contra de las, barricadas y del desorden. Transcribo algunos párrafos de este llamado a la calma:

"Para los dirigentes de una revolución que, por el momento, no, tiene objeto, el problema de las elecciones no existe. Lo que quieren y no lo esconden, es echar abajo la casa. Toda tentativa de solución, comprendidas las elecciones, es para ellos una traición, todo llamado al orden más elemental, es una provocación. Su triunfo sería el del más puro nihilismo y nadie puede saber hasta dónde nos conduciría la tragedia... Es tiempo ya que el conjunto de estudiantes que ha demostrado su valor notifique a los responsables que, sin abandonar sus justas reivindicaciones, no los seguirán a cualquier parte" 
Abandonados por el Partido Comunista y por la Federación, que - desean elecciones tranquilas, por la opinión pública cansada de violencia, por los comerciantes, afectados en sus intereses, por la burguesía aterrada, los estudiantes sólo han seguido contando con el apoyo del minúsculo PSU y de parte de los obreros jóvenes pertenecientes a la CEDT. La política del "pourrissement" (pudrición) ha producido sus resultados.

Con todos estos factores favorables el Gobiemo estimó llegado el momento de avanzar un nuevo paso. Después de haber prohibido todas las manifestaciones públicas clurante el periodo electoral, aplicó una ley de 1936, dictada contra los "Croix cle Feu" y los "Cagoulards" (organizaciones de extrema derecha que habían provocado grandes disturbios en aquel año) y' procedió a disolver a las prin. cipales organizaciones extremistas de Izquierda.

Dichas organizaciones son: la Juventud Comunista Revolucionaria, fundada en 1966 por un grupo de estudiantes que se negaron a seguir al Partido Comunista cuando éste apoyó la candidatura presidencial de François Mitterand; la Unión Comunista. "Voz Obrera", que preconiza la creación de una Cuarta Internacional; el Comité de Unión de Estudiantes Revolucionarios, de tendencia marcadamente trotzkista, fundado en 1961; la Unión de las Juventudes marxistas-leninistas, formada por estudiantes e intelectuales expulsadọ del Partido Comunista, que en un comienzo siguieron las enseñanzas de Althusser y son ahora francamente maoistas; finalmente el "Movimiento 22 de Marzo", anarquista, formado por Henri Cohn-Bendit.

La medida de disolución decretada por el Gobierno puede ser contraproducente. En efecto, los miembros de los grupos afectados han entrado de lleno en la clandestinidad, la cual tiene, para la Juventud, un atractivo especial. Como no se trataba de organizaciones propiamente tales, con fondos y locales apropiados, nadie podrá impedir que prosigan los contactos entre sus miembros que podrán actuar en una resistencia política, parecida a aquella de que tanto han oído hablar a la generación anterior. Impeclidos de manifestar en las calles y de enfrentarse con la Policía, los estudiantes pueden iniciar un tipo de acción nihilista y de atentados aislados. Para ellos, en efecto, las elecciones equivalen a una traición y este sentimiento lo han demostrado procediendo a quemar, cuando han podido, la propaganda electoral.

El teatro Odeón fue abanclonado sin resistencia por sus ocupantes debido a las plagas de insectos y de ratas que se habían apoderado del local. En cuanto a la Sorbonne, los estudiantes, clespués de haber expulsado a un grupo de "Gorilas" llamados los "katangueses", 
que habian sido útiles en un momento como fuerzas de choque y que, en seguida, pretendieron adueñarse también del edificio, han llamado a las autoridades sanitarias para Juchar contra los microbios y las ratas. Estos "katangueses", aventureros provenientes de la Legión Extranjera, ex paracaidistas de las guerras del Vietnam y de Algeria o ex mercenarios al servicio de Tshombe, hicieron gran daño y perjudicaron la reputación de los "rabiosos". Después de esta desinfección moral que significó su expulsión, ha veniclo la desinfección material de la famosa Universidad. Todo ello ha traído en el ánimo. de los estudiantes la frustración y la desesperación que son las peores consejeras. Por ello es que creo en las manifestaciones esporádicas. y aisladas en contra clel orden establecido y del sistema político. democrático.

Puede muy bien reaparecer el nihilismo que tantos adeptos tuvo aquí en el siglo pasado y aun en los primeros años del actual.

\section{EN VISPERAS DE ELECCIONES}

\section{6 de junio}

Una extraña situación caracteriza a la vida política en esta víspera de elecciones. Mientras el Gobierno, que ha hecho del orden un sistema, desea que este no se mantenga totalmente inalterable, la Izquierda, y sobre todo el Partido Comunista, son los mayores enemigos de cualquier desorclen. Para el Gobierno, la calma total puede significar un desbande en el "Partido del MFiedo", con cuyo aporte masivo cuenta para las elecciones. En el fondo, desearía que el clima de intranquilidad se mantuviera durante los próximos quince días; pero una intranquilidad controlable, que no llegase a favorecer la abstención. En cambio, la- Tzquierda, temerosa de que el electorado la asocie a los últimos graves incidentes, desea demostrar que ella es la mejor garantía de la tranquilidad, la cual puede verse de nuevo afectada si el Gobierno obtiene un amplio triunfo.

La plataforma electoral del gaullismo será el anticomunismo y la "participación" Pero, en verdad, fuera del sector izquierdista de la actual mayoría, dirigido por el Ministro Capitant y que preconiza reformas socio-económicas urgentes, la campaña gubernativa se ha hecho sobre todo sobre la base del anticomunismo, lo que parece ser más rentable. Quiere aprovechar la oportunidad para obtener una mayoría sólida y homogénea y no ha vacilado en presentar candidatos contra sus aliados "giscardianos". Estos últimos temen perder electores que antes les favorecían y que, a raíz de los acontecimientos de mayo, votarian por los gaullistas puros. Por eso, tien- 
den la mano hacia su ala izquierda, es decir hacia el Centro Demócrata. Además, insisten en la necesidad de ampliar la mayoría y de hacer ingresar al Gobierno aun a algunos miembros del ala derecha de la Federación.

El Centro Demócrata asustado por la bipolarización política, evita atacar al régimen, pero pide también la ampliación de la mayoría actual y la formación de un Gobierno de unión nacional reformista y anticomunista.

La Federación, por su parte, busca también los contactos con el Centro Demócrata, cuyo apoyo puede serle indispensable en el segundo escrutinio, trata de explicar al electorado que su pacto con los comunistas no significa en modo alguno el sometimiento a Moscú y que Francia no será una nueva Checoslovaquia.

El propio Partido Comunista se ha ceñido la bandera tricolor y se presenta como un partido de orden, reformista y antiextremista. Al inaugurar la campaña electoral, el Secretario General, Waldeck Rochet, ha declarado textualmente: "El Particlo Comunista es un partido de orden y de sabiduría política, y ha hecho un llamado a la disciplina obrera libremente aceptada... Al denunciar las provocaciones de cualquier lado que provengan, hemos obradi con. discernimiento para cerrar el camino a la aventura sangrienta e impedir la instauración de la clictadura militar"... "Los gaullistas. tratan - dijo más adelante- de cubrirse con la bandera tricolor. Pero. la bandera tricolor no es la propiedad exclusiva de nadie y, sobre. todo, de quienes han sacrificado los intereses de la masa de los franceses a los privilegios de un puñado de multimillonarios".

Por último, es digno de mencionar que el Gobierno se abstuvo. de disolver el Movimiento extremista de Derecha, "Occidente", que: es, sin embargo, bien revoltoso. Si a esto se agrega la liberación del General Salan y de los últimos presos condenados a perpetuidad, te la OAS, se puede llegar a la conclusión de que han existido c. ntactos entre el Gobierno y la Extrema Derecha Petainista y OAS, y que eran fundadas las acusaciones lanzadas contra Tixier-Vignancour de convivencia con el gaullismo. Esta extrema derecha no. cuenta con más de un cinco por ciento del electorado; pero ese pequeño aporte puede ser esencial para el gaullismo en los cornicios del domingo 23.

¿Cuál será el resultado de estas elecciones? En la situación ạctual es imposible hacer cálculos serios. Todo parece indicar que el. gaullismo y el comunismo, los dos extremos, debieran ser los mayores beneficiados con la bipolarización. Sin embargo, los contactos que se están produciendo, por temor a ella, entre "giscardianos", CentroDemócrata y Federación, puede hacer cambiar estas previsiones. 
Será necesario esperar el primer escrutinio del domingo próximo para ver más claro.

Un triunfo demasiado preciso, y bien probable, del Gobierno, puede significar el abandono de la ampliación de su base, que estimo necesaria para la tranquilidad política; $y$, lo que es más preocupante, el abandono de las reformas de estructuras indispensables si se quiere evitar la repetición de los últimos acontecimientos en un plazo más o menos breve.

Un triunfo de la Oposición, significaría una crisis presidencial con consecuencias gravísimas.

Una elección sin vencedores ni vencidos no resolvería los actuales problemas.

Creo, para la estabilidad de Francia, actual y futura, que sería conveniente un triunfo del gaullismo y una intervención personal del General Charles de Gaulle destinada a ampliar la base de Gobierno hacia su Izquierda y a introducir las reformas de las cuales él mismo ha sido siempre partidario, pero que no ha sido capaz de imponer durante los últimos años de su gobierno a sus colaboradores, impregnados de conservantismo social y económico.

Sin embargo, me asalta una duda: ¿No querrá el General Charles de Gaulle aprovechar un triunfo electoral para salir airosamente de su cargo, para entregar el país a manos jóvenes, cierto es, pero menos expeditas, y menos prestigiosas, con menor autoridad y menor disposición de ánimo para introducir esas reformas que tanto se necesitan? Un gesto así del General no me extrañaría. A él le preocupa sobre todo, su imagen en la Historia. Sería tal vez la mejor manera de conservarla en un sitio preponderante si se alejara voluntariamente del poder después de un verdadero plebiscito en su favor.

La verdad es que esta posibilidad de un retiro del General no se la he oído a nadie. Se me ha ocurrido sólo a fuerza de estudiar la psicología de tan extraño y apasionante personaje.

Lo veo muy bien, triunfador en las elecciones, enviando un Mensaje a la Nación que contenga su testamento político y retirándose a. Colombey-les-deux-Eglises para terminar sus Memorias y esperar allí, después de haber viajado tanto, el inicio de la eterna Jornada.

Pero, aparte de estas elucubraciones sobre lo que el General Charles de Gaulle podría hacer en caso de ganar las elecciones parlamentarias, lo que, siendo probable, no es seguro, insisto en que los problemas de Francia, sacados a la luz del día e incrementados por los últimos acontecimientos, no van a tener solución fácil.

Si bien es cierto que el Jefe del Estado, mediante una actitud de firmeza logró sacar al país, a la hora undécima, de la revolución social y de la anarquía, los problemas, sean ellos sociales, educacio- 
nales o financieros, han tenido soluciones transitorias y no de fondo. Sería, a mi juicio, un gravísimo error pensar que con la disolución de la Asamblea Nacional y la convocación a elecciones, los peligros han siclo descartaclos.

Este país ha sido profundamente afectado por una crisis que se cierne sobre todo el Occidente, la crisis de la sociedad de consumo. $\mathrm{Si}$ los franceses conservan la imaginación y el sentido de futuro que les caracterizó en el pasado, serán capaces de encontrar nuevas soluciones a nuevos problemas. Pero, si, como lo temo, creen quie todo ha sido solucionado porque el orden ha sido restablecido, nutevos $\mathrm{y}$ más graves acontecimientos se producirán más temprano que tarde. Si no sacan ni el Gobierno, ni los partidos políticos, ni la clase dirigente, la verdadera y profunda lección de la verdadera "Fevolución cle Mayo", tan importante como las de 1830 y 1848, Francia verá, por ceguera y comodidacl, el ocaso cle su influencia espiritual en el mundo.

Acabo cle saber que esta tarde la Sorbonne ha sido también evacuada por los estudiantes. No porque flota la bandera tricolor en lugar de la roja $y^{\prime}$ de la negra, el problema de la juventud ha terminado.

\section{7 de junio}

A raíz cle los incidentes estudiantiles, numerosos extranjeros han siclo expulsados del país, entre ellos un chileno, que no alcanzó a prevenirme. Otro, sin embargo, que huyó del hospital adontle había sido trasladado después de su cletención, no pudo ser notificado de su expulsión. Recurrió a la Embajada y le aconsejé que se escondiera. Mis gestiones ante el Quai d'Orsay no tuvieron éxito debido a que numerosos colegas Embajadores habian tratado de obtener, sin resultado, que se clejara sin efecto el decreto de expulsión. No poclian hacer una excepción única para Chile. Pero, decido aprovechar mi amistad personal con el Prefecto de Policía, Grimaud, y obtengo con él que no se clé curso al decreto en virtud de la falta de notificación personal al afectado. Le confesé a Grimaud que yo mismo le había aconsejado a mi compatriota esconderse. Sonriente -es un hombre muy fino $y^{\prime}$ agraclable- me contestó que yo habia tomado una grave responsabilidad... pero que había salvado a $\mathrm{mi}$ compatriota. 


\section{4 de junio}

Ayer se celebró el primer escrutinio de las elecciones para la Asamblea Nacional. Votó un $80 \%$ de los inscritos, lo que es normal en una elección de esta importancia. Mientras en las elecciones de marzo de 1967, sólo 81 candidatos obtuvieron la mayoría absoluta y fueron, por tanto, elegidos, esta vez, hay 164, de los cuales 122 pertenecen al gaullismo puro y 28 a los "giscardianos". Los comunistas eligen sólo 6 y el Centro Demócrata 4. Los independientes de derecha eligen 2 y hay 2 sin partidos

Este resultado corresponde sólo en parte al número de sufragios obtenidos por los partidos políticos y ello debido al sistema electoral francés, que no es proporcional.

El Partido Comunista pierde, en un año, 600.000 electores y su porcentaje baja de $22,51 \%$ a 20,03\%. Obtiene, sin embargo, 4.435 .000 votos.

El P.S.U. en cambio, como partido más extremista, gana 380.000 votos y obtiene 875.000 , pasando del $2,21 \%$ al $3,94 \%$.

La Federación de Izquierda pierde 620.000 votos y obtiene sólo 3.654 .000 ( $16,5 \%$ en vez de $18,96 \%$ ).

El Centro Demócrata, obtiene cerca de 2.300 .000 votos pero pierde 530.000 en relación a las elecciones del año pasado y pasa del $12,64 \%$ al $10,34 \%$.

Los gaullistas y giscardianos, que iban juntos, son los grandes triunfadores. Obtienen casi 9.700 .000 votos y ganan 1.200 .000 en relación al año pasado y pasan del $37,73 \%$ al $43,65 \%$.

Estos resultados pueden, ser modificados por el segundo escrutinio. En efecto, en muchas circunstancias, el Centro Demócrata va a decidir entre un gaullista y un candidato de la Federación. Seguramente esto va a dar lugar a compensaciones que permitirán al Centro no desaparecer del escenario político, aunque su líder, Jean Lecanuet, está en mala posición en Rouen.

El gaullismo puede también sufrir las mismas malas consecuencias en el segundo escrutinio, derivadas de su mismo triunfo en el primero. El año pasado, muchos electores no votaron el segundo domingo, dando por descontada la victoria de su candidato. Como algunas elecciones se presentan muy estrechas, será necesario movilizar el máximo de fuerzas para el 30 de junio próximo.

A pesar de esta cluda y de la actitud que pueda adoptar el Centro Demócrata en cada caso, es seguro que la mayoría gaullista será amplia en la próxima Asamblea, y que la influencia de los giscardianos 
será menos importante. Si se repiten las cifras, es aún posible que los gaullistas puros alcancen la mayoría absoluta.

El triunfo del gobierno ha sido tan visible que existe preocupación cle que, en el segundo escrutinio, muchos electores deseen compensarlo favoreciendo a algunos candidatos del Centro Demócrata.

A ello se debe una cleclaración del Primer Ministro Georges Pompidou asegurando que está clispuesto a acoger en la Mayoría a aquellos centristas que deseen colaborar con el General y no sean rehenes del Partido Comunista.

Es indudable que el "Partido del Miedo" desempeñó el papel que de él se esperaba. Atemorizados por los acontecimientos de mayo y galvanizados por el discurso último del General, no han trepidado, cualesquiera que sean sus opiniones políticas, en dar su roto a los candidatos de la confianza de Charles de Gaulle.

Digno de anotarse es, en los barrios obreros, el aumento de los sufragios gaullistas. Ello explica las pérdidas del Partido Comunista, que no sólo fueron compensadas por el incremento del PSU, sino que se transfirieron al candidato gobiernista. Ello no obsta para que el Partido Comunista francés siga contando con cuatro millones y medio de sufragios y siga siendo, clespués del italiano, el más fuerte de Europa Occidental.

Más dignos de consideración son los seiscientos mil votos menos que obtiene la Federación. La causa hay que buscarla en la actitud doble de François Mitterand durante los últimos acontecimientos.

GANÓ LA BANCA

\section{Io cle julio}

Un mes exactamente después que el General Charles de Gaulle, en un esfuerzo de última hora, lograba recobrar las riendas del poder que habia estado prácticamente vacante clurante 48 horas, en el transcurso de las cuales sus adversarios discutían públicamente la mejor forma de reemplazarlo revolucionariamente, el electorado francés le ha otorgado, en forma "ultra petita", su confianza, en forma tan amplia como peligrosa.

Si el primer escrutinio del 23 de junio, había clado a entender cuál sería, en forma irreversible, la tendencia del electorado, nadie esperó que el segundo, el escrutinio de la reflexión, aumentara aún el margen de la confianza de la ciudadanía en el General. El Gobierno temía que el éxito considerable logrado entonces pudiera ser frenado una semana más tarde, tal como sucedió en las elecciones del año pasado, con el objeto de no entregar la herramienta sin 
contrapeso en manos del Ejecutivo y de no transformar al Parlamento en una mera Cámara de "toma de razón". Temía también que la participación electoral bajara por coincidir el segundo escrutinio con el inicio de las vacaciones de verano que tanto importan a los franceses, y que muchos de sus partidarios, dando su triunfo por descontado, prefirieran las delicias del mar a la canícula de las grandes ciudades. Tales temores indujeron al propio General a hacer, por radio y televisión, un último llamado al electorado la víspera misma de la segunda elección.

Pero, lejos de producirse un cambio, el triunfo del gaullismo se acentuó aún más en las elecciones de ayer. Los resultados de ambos escrutinios arrojan para los dos partidos de gobierno ("ortodoxos" y "giscardianos") 358 elegidos, sobre 467. Los "gaullistas puros" obtienen la mayoría absoluta con 294 diputados y ganan 97 asientos. En cuanto a los giscardianos, ganan 21 diputados y ven su número pasar de 43 a 64; pero su apoyo condicional no es ya indispensable.

La derrota de los demás particlos se transforma en un verdadero desastre. La Federación piercle 61 de sus 121 diputados y el Partido Comunista baja de 73 a 34 . En cuanto al Centro Demócrata, que tenia 42 representantes, consigue sólo 27 y su líder, Jean Lecanuet, es derrotado ampliamente. El PSU, de extrema izquierda, no obtiene ningún diputado y pierde los 3 que tenía. Lo que es peor, Pierre Mendes-France, su figura más representativa, es reemplazado por un gaullista de viejo estilo, Jeanneney, en cuyo triunfo nadie creía.

Es indudable que el gaullismo recibió el apoyo masivo del "Partido del Miedo". Asustados por la conmoción de mayo, que afectó a todo el país, los franceses y francesas se unieron junto al único hombre que, aunque tardíamente, demostró resolución, carácter y coraje. Las ideologías diferentes y los odios acumulados se borxaron cuando se trató de restablecer el orden. Un examen más detallado de los escrutinios demuestra que el gaullismo progresó en los barrios de pequeños comerciantes y aun obreros que le eran abiertamente hostiles Más aún, por primera vez, se borran las fronteras del Loira. En efecto, por tradición, al Norte de dicho río, Francia es en su mayoría derechista $y$, al Sur, izquierdista. Ahora, el gaullismo penetra en las fortalezas más tradicionales clel Socialismo, del Comunismo y del Radicalismo.

El Pacto electoral Federación-Partido Comunista no funcionó como el año anterior. El examen de los escrutinios demuestra que los electores de la Federación no se volcaron en el segundo escrutinio en favor del candidato comunista y viceversa. En cuanto a los electores del Centro Demócrata, cuando tuvieron que elegir entre un 
gaullista $y$ un opositor, se inclinaron casi unánimemente por el primero. $Y$ cuando la Oposición tuvo que pronunciarse entre un centrista y un gaullista, no apoyó en forma cerrada al primero.

El sistema electoral francés, tan alejado del proporcional a que estamos acostumbrados en Chile, favoreció al Gobierno en forma tal vez exagerada. Por eso, es importante considerar no sólo el número de diputaclos electos, sino que también el número de sufragios.

En el primer escrutinio, los dos particlos del Gobierno lograron, en cifras redondas, 10.500 .000 votos y obtuvieron 152 diputados, mientras que la Federación, el Partido Comunista y el PSU, con 9 millones de votos, sólo obtenían 6 diputados.

En el segundo escrutinio, con un electorado más reducido, el Partido Comunista logra 28 diputados con cerca de 3 millones de votos; la Federación obtiene, en cambio, 57, con 3.100.000 sufragios y los gauIlistas (ortodoxos y giscardianos) 206 diputados con 6.800 .000 votos.

A su vez, el Centro Demócrata, con 1.150 .000 votos, saca 22 diputados.

Si se observan, por lo tanto, las cifras de votos, el resultado es mucho menos favorable al Gobiemo que to que indican las apariencias.

Ello explica también que las elecciones hayan sido muy reñidas y que con un electorado de cerca de 14. millones, hubo vencedores $y$ vencidos con diferencias de 9,4 y aun 1 votos...

La alianza Federación-Particlo Comunista está virtualmente quebrada. Quedó ahora de manifiesto que una gran parte de radicales y de socialistas no aceptan una combinación de gobierno con los comunistas. Si la alianza electoral surtió efectos el año pasado, era porque no existía un pacto de gobierno, como lo quería François Mitterand y Waldeck Rochet.

François Mitterand es elegiclo, con dificultades, en el segundo escrutinio y todos sus lugartenientes que contaban con su patrocinio personal, son derrotados. Su prestigio político se ve muy afectado y disminuido. La Izquierda se queda sin líder político.

Los gaullistas, con una excepción, ganan en todas las circunscripciones de París y recuperan, con creces, gran número de diputaciones que habian perdido el año pasado en el famoso "cinturón rojo" de la capital.

Terminadas estas anotaciones, es del caso preguntarse dy ahora qué? $\mathrm{El}$ Gobierno tiene en sus manos las herramientas constitucionales y: mañana tendrá las herramientas legales que la amplia mayoría le va a otorgar para gobernar, seguramente, mediante facultades 
extraorclinarias $\mathrm{Y}$ hacer frente a las consecuencias económicas $y$ financieras de la "Revolución de Mayo"

Ya no necesitará ni tan siquiera del "oui... mais" (sí... pero) de los giscardianos.

Pero no basta tener la mayoría y resolver los problemas inmediatos. Las mismas causas producen, según dicen, los mismos efectos y si no se modifican las causas podremos tener, de aquí a poco, efectos parecidos a los que ýa conocimos hace cinco semanas apenas.

Si el General Charles de Gaulle no logra imponer su criterio social y establecer la "participación" tan anunciada y de la cual es él personalmente partidario, habrá perdido la más notable de sus victorias. Si el círculo reaccionario que lo ha rodeado hasta ahora le impide hacer las transformaciones necesarias y establecer más justicia y menos desigualdad, bien puede transformar su Austerlitz de ayer en un Waterloo futuro.

El electorado francés, como el de otros países, le ha entregado, junto con una gran mayoría, la solución de sus problemas. Le dará un plazo prudencial para ello. El problema reside en que por él han rotado Ios ultracapitalistas, la clase media, la alta burguesía, los reformistas $y$ aun algunos avanzados que creen en la virtud de la democracia y no en las barricadas. ¿Cuál de todas estas tendencias opuestas predominará y cuáles quedarán defraudadas o heridas en sus intereses?

No estoy en situación de decirlo. Confío sí en el General que supo sacar las vercladeras conclusiones de los acontecimientos de mayo y las señaló con claridad en su última entrevista de prensa. Espero que se busque la solución a problemas que no sólo se plantean aquí, sino que en todas las regiones del mundo, y que son, en el fondo, el resultado de una crisis de la sociedad. Confío en que los franceses que, antes de la Quinta República, votaron siempre por la Izquierda para practicar una política de Derecho, hayan elegido ahora una mayoría de Derecha para practicar una política de Izquierda. Tal vez la reorganización ministerial que se ve venir para los próximos días dé una indicación sobre el futuro.

En todo caso, seguimos viviendo en Francia acontecimientos interesantísimos, aunque no siempre congruentes. A raíz de las últimas elecciones, uno llega a preguntarse si no hay dos pueblos fran ceses: uno que se bate un día en las barricadas y otro que, al día siguiente, deposita su cédula en las urnas.

P.S. La actitud del Partido Comunista en los acontecimientos de mayo y junio y el resultado de las elecciones, tan desfavorables para él, me hacen recordar el consejo, que creo es de Maquiavelo, de que "nunca hay que amedrentar si no se está clispuesto a golpear en seguida". 